IZA DP No. 4341

Marriage, Cohabitation and Commitment

Murat lyigun

August 2009 


\title{
Marriage, Cohabitation and Commitment
}

\author{
Murat lyigun \\ University of Colorado, \\ CID, Harvard University and IZA
}

Discussion Paper No. 4341

August 2009

\author{
IZA \\ P.O. Box 7240 \\ 53072 Bonn \\ Germany \\ Phone: +49-228-3894-0 \\ Fax: +49-228-3894-180 \\ E-mail: iza@iza.org
}

Any opinions expressed here are those of the author(s) and not those of IZA. Research published in this series may include views on policy, but the institute itself takes no institutional policy positions.

The Institute for the Study of Labor (IZA) in Bonn is a local and virtual international research center and a place of communication between science, politics and business. IZA is an independent nonprofit organization supported by Deutsche Post Foundation. The center is associated with the University of Bonn and offers a stimulating research environment through its international network, workshops and conferences, data service, project support, research visits and doctoral program. IZA engages in (i) original and internationally competitive research in all fields of labor economics, (ii) development of policy concepts, and (iii) dissemination of research results and concepts to the interested public.

IZA Discussion Papers often represent preliminary work and are circulated to encourage discussion. Citation of such a paper should account for its provisional character. A revised version may be available directly from the author. 


\section{ABSTRACT}

\section{Marriage, Cohabitation and Commitment ${ }^{\star}$}

This paper combines partner matching with an intra-household allocation model where couples decide if they want to marry or cohabitate. Marriage encourages but does not ensure a higher level of spousal commitment, which in turn can generate a larger marital surplus. Individuals' marital preferences and commitment costs vary, and sorting equilibria are based on individuals' marital preferences and propensity to commit. In all equilibria, some married couples are able to cooperate and operate efficiently, but some married and all cohabiting couples act with limited commitment and non-cooperatively. When spousal marital commitment costs are gender symmetric, there is a pure-sorting equilibrium in which all partners who prefer to act with commitment in marriage are matched with someone who has the same preference. In such an equilibrium, the benefits of marital commitment accrue to both partners. When commitment costs are not gender neutral, there can also be mixedmatching equilibria in which a partner who is willing to act with commitment in marriage is matched with someone who is not. In all such equilibria, the benefits of marital commitment accrue only to those men or women who are in short supply. Consequently, a shortage of men (women) who can maritally commit makes all women (men) worse off and materially indifferent between marriage or cohabitation. An excess supply of men who prefer marriage not only reduces the marriage incentives of men and raises those of women, but also the marital commitment incentives of men. As a corollary, if the gains from marriage fall, not only will more individuals choose to cohabitate but more married couples will act noncooperatively.

JEL Classification: C78, D61, D70

Keywords: collective model, intra-household bargaining, modes of partnership choice

Corresponding author:

Murat lyigun

Department of Economics

University of Colorado

Boulder, CO 80309-0256

USA

E-mail: murat.iyigun@colorado.edu

\footnotetext{
* I am grateful to Pierre-Andre Chiappori and Yoram Weiss for their critical intellectual input but, of course, all the remaining errors are mine alone.
} 


\section{Introduction}

A fundamental question in family economics is the degree to which partners in a longterm relationship - be it marriage or cohabitation - can cooperate and act with some level of commitment. While we do not yet have a consensus on this issue, whether marriage typically involves fully cooperative spousal behavior or limited to no spousal cooperation has profound normative as well as positive implications. ${ }^{1}$

The propensity to cohabitate has secularly risen in most, if not all, industrialized countries in the last decades, with a commensurate decline in the marriage rates. Cohabitation used to be rare in most countries until recently, which is why relevant data remain scant. But Chiappori et al. (in progress, Ch. 1), provide some evidence from Denmark and the United States. Accordingly, cohabitation is more common amongst the young and the propensity to cohabitate for all age groups is higher now than it was twenty years ago. Within each age group, married couples have more children than cohabiting couples who in turn have more children than singles. Moreover, the proportion of cohabiting couples declines sharply with age. Hence, we have some evidence that cohabitation is an imperfect substitute for marriage, with cohabitation involving a lower level of commitment.

The existing literature does make a distinction between legal marriage and nonmarital cohabitation in so far as the former reflects commitment and the latter does not. Beyond that, however, there isn't much to distinguish marriage from cohabitation or the extent to which spousal commitment levels are endogenous and they could vary within the institution of marriage itself. But to the extent that commitment is not synonymous with legal marriage and individuals could differ in their attitudes toward cohabitation and marriage, the trends in marriage, cohabitation as well as spousal commitment ought to coevolve and they should be jointly analyzed. Put differently, the fact that marriage as an institution generally reflects a higher level of spousal commitment does not suggest that the behavior of married and cohabiting couples could be analyzed in isolation from each other.

In fact, if marriage and cohabitation are imperfect substitutes and the choice of partnership commitment could vary within marriage too, then it is important to identify the conditions under which some couples choose to marry and act cooperatively,

\footnotetext{
${ }^{1}$ For further details on the links between commitment and efficiency, see Chiappori et al. (2008), Browning (2009), Lundberg and Pollak (2003, 2009) and Matouschek and Rasul (2008).
} 
while others decide to marry with a lower level of commitment or simply cohabitate, mostly refraining from a commitment to a longer-term relationship. Such a quest requires a unified framework according to which marriage and cohabitation as well as cooperative and non-cooperative spousal behavior can coexist in equilibrium and individuals choose not only their (desired) marital status but their optimal modes of behavior. The objective of this paper is to develop one such model.

In what follows, I present a model of marriage versus cohabitation and marital commitment versus limited commitment in determining intra-household choices and allocations. In the model, couples match to form partnerships, and individuals vary according to their preferences for marriage and costs of commitment to cooperate in marriage. Unlike cohabitation, marriage encourages but does not ensure a higher level of spousal commitment, which in turn can generate a larger marital surplus. Individuals' marital preferences and commitment costs vary, and sorting equilibria are based on individuals' marital preferences and propensity to commit.

Married and committed couples act cooperatively in determining their intrahousehold allocations. As a result, when two partners with low commitment costs marry, they abide by efficient household choices and allocations. But when two individuals with high commitment costs and marriage preference match, they decide to marry although they may not cooperate, whereas a match of two high-cost, lowmarriage preference individuals results in cohabitation. In contrast, if an individual with a high commitment cost marries a spouse whose cost is relatively low, the former can take advantage of his partner's decision and extract all of the surplus generated by their marriage.

The essential idea here is that a committed spouse makes a costly — and, perhaps, marriage-specific investment - which leaves her vulnerable to opportunistic spousal behavior. When spousal choices such as labor supply and production specialization influence not only household incomes but allocations within it, cooperative behavior would be harder to sustain because it could be costly for household members to commit to efficient choices. Indeed, there are empirical findings which suggest that spousal specialization and labor force detachment influence spousal threat points. ${ }^{2}$

\footnotetext{
${ }^{2}$ For example, married men work longer hours in the market and have substantially higher wages than unmarried men, and married women work less and have lower wages compared to single women. Together these findings imply that wives who commit most or all of their time to domestic production could be worse off in divorce whereas husbands who work full time could be better off. See Gronau
} 
On this basis, I assume married couples with divergent commitment costs as well as all cohabiting couples resort to a non-cooperative Nash-Cournot game. Due to a lack of commitment to abide by agreed upon courses of spousal action, such couples make inefficient choices in the conventional sense. I investigate the rational-expectations equilibrium that arises under such circumstances.

The main findings that emerge from the model are as follows: In all equilibria, some married couples are able to cooperate and operate efficiently, but some married and all cohabiting couples act with limited commitment and non-cooperatively. When spousal marital commitment costs are gender symmetric, there is a pure-sorting equilibrium in which all partners who prefer to act with commitment in marriage are matched with someone who has the same preference. In such an equilibrium, the benefits of marital commitment accrue to both partners.

The important implication of this is that when there is a mixed matching equilibrium with, say, committed husbands in short supply, men's marital commitment incentives will be higher because committed women compete more intensely for committed husbands. Alternatively, an excess supply of men who prefer marriage not only reduces the marriage incentives of men and raises those of women, but also the marital commitment incentives of men. In such mixed-matching equilibria, the benefits of marital commitment accrue only to those men or women who are in short supply and a shortage of men (women) who can maritally commit makes all women (men) worse off and materially indifferent between marriage or cohabitation. Hence, even though allocations and outcomes in uncommitted partnerships are mostly unresponsive to market forces, the degree to which the institution of legal marriage manifests spousal commitment and cooperation is driven by individual attitudes toward cohabitation, marriage and spousal commitment as those are manifested in market dynamics.

If the gains from marriage fall-for example, due to technological change which diminishes the returns to scale from cohabitation, a la Greenwood, Seshadri and Yorukoglu, 2005 - then not only will more individuals choose to cohabitate but more married couples will act non-cooperatively. In this, we shall see that structural (1986), Daniel (1992), and Korenman and Neumark (1992). For a detailed overview, see Weiss (1997).

Furthermore, recent time-use statistics reveal that women work significantly longer hours at home than men, even though their hours worked in the labor market have converged in the last three decades. For details, refer to Aguiar and Hurst (2006). 
changes in partner matching or household production impact marriage and cohabitation patterns as well as the intra-household allocations of cohabiting and married couples.

\section{Related Literature}

Despite the rising prevalence of cohabitation at the expense of marriage, cohabitation has garnered far less attention. In fact, most existing models do not distinguish between legal marriage and non-marital cohabitation and for all practical purposes the two forms of household partnership are typically lumped as one. One recent exception is provided by Gemici and Laufer (2009) which posits and estimates a dynamic model of household formation and dissolution as well as fertility and labor supply. This paper, along with the work below, represents an inaugural attempt to explicitly model non-marital cohabitation as an intermediate stage between marriage and singlehood. More generally, both papers take stock of the interlinkages between various partnership modes and the options of marriage versus cohabitation available to individuals in analyzing the dynamics of marriage and cohabitation against the backdrop of varying levels of commitment.

The traditional approach to analyze household choices takes the family as the prime decision-making unit. ${ }^{3}$ The non-unitary household models provide an alternative to this approach by treating the individual members of the family as the core decision-makers. Starting in the early 1990s, empirical evidence in support of the non-unitary model began to accumulate. ${ }^{4}$ Consequently, the non-unitary household models have emerged as the compelling theoretical alternative for analyzing the economics of the family.

There are three classes of non-unitary models in the existing literature: First, we have the 'collective models' where household members act with commitment and cooperation to choose from a host of Pareto efficient choices. The generalized underpinning of this model was provided by Becker (1981) and Chiappori (1988, 1992). A closely related strand involves the 'cooperative bargaining models' in which a cooperative process - typically, although not exclusively, the Nash bargaining paradigm-

\footnotetext{
${ }^{3}$ Samuelson (1956) and Becker (1981).

${ }^{4}$ See, for example, Browning et al. (1994), Lundberg et al. (1997), Chiappori (1998), Chiappori et al. (2002), and Udry (1996).
} 
determines household allocations. The seminal examples in this category include Manser and Brown (1980), MacElroy and Horney (1981), and Sen (1983). And third, we have models of non-cooperative or Nash bargaining where household members choose their actions taking as given those of other family members. Some examples in this line are Lundberg and Pollak (1993), Chen and Woolley (2001), Maher and Wells (1998) and Basu (2006).

While the existing literature has traditionally sideswiped the distinction between legal marriage and non-marital cohabitation, it has been far more cognizant of the issue of commitment and cooperation in partnerships. Indeed, regardless of whether the couple is cohabiting or married, a perennially important issue revolves around the extent to which household choices are made with some commitment and efficiently or inefficiently due to a lack of commitment. When spousal choices involve costly commitment and, hence, they affect the household balance of power, one can no longer restrict attention to the efficient frontier. Since commitment to cooperate is potentially costly and it introduces a hold-up problem, repeated interactions and an appeal to the Folk theorem would not help to restore efficiency either. In such cases, the plausible alternative is to model spousal behavior as a non-cooperative bargaining process that can stray from efficient outcomes. For examples of such models, see Lundberg and Pollak (1994, 2003), Rasul (2005), and Iyigun and Walsh (2007a).

Although we lack a theoretical underpinning of marital commitment versus noncooperative bargaining, recent empirical work has made attempts to identify the valid mode of intra-household actions. For example, Del Boca and Flinn (2005) estimate a structural model and find some weak evidence in favor of the collective mode of behavior among couples in the United States. In contrast, Mazzocco (2007) presents an empirical test of intra-household commitment and, using PSID data, rejects the hypothesis that household members can commit to future allocations of resources.

This paper also shares some similarities with a burgeoning strand in the economics of the family literature which incorporates some aspect of pre-marital decisionmaking (such as educational attainment) and spousal matching into a model of intrahousehold decision-making. Recent examples include Peters and Siow (2002), Browning et al. (2003), Chiappori et al. (forthcoming) and Iyigun and Walsh (2007b).

The remainder of this paper is organized as follows: In section 3, I present the 
generic model. In Section 4, I discuss a specific example in which couples can cooperate by specializing in home production and labor market work. In Section 5, I conclude.

\section{The Basic Model}

\subsection{Assumptions}

The populations of men and women are large and equal in mass. ${ }^{5}$ Men and women are completely identical in their preferences and opportunities and they all live for one period. At the beginning of the period, individuals decide whether they want to live with a partner or stay single. Those who prefer to live with someone then enter a matching market in order to find a mate. Competition over mates determines who matches with whom. These assignments, together with the known individual characteristics described below, guides the individuals' decisions to marry or cohabitate. Married couples also choose their levels of spousal commitment, which in turn influences their material surplus.

\subsection{Marital Commitment vs. Cohabitation}

Each partner who lives together with someone takes an action, such as deciding how much to work at home and in the labor market or how much time to allocate to childrearing. The actions of each partner influences the surplus a married or cohabiting couple could generate jointly.

I denote a particular man by $i$ and a particular woman by $j$. All individuals of a given gender produce the same material output when they are single, but singles' output level may differ by gender. I denote the material utility of a single man $i$ by $\zeta_{m}$ and that of a single woman $j$ by $\zeta_{w}$.

Definition 1 A couple $\{i, j\}$ takes the actions $a_{i}, a_{j} \in[0,1]$ to produce the joint material output given by $\zeta_{i j}=\zeta\left(a_{i}, a_{j}\right)$. The material output $\zeta_{i j}=\zeta\left(a_{i}, a_{j}\right)$ is twice differentiable and concave in $a_{i}$ and $a_{j}$ with $\left\{a_{i}^{M}, a_{j}^{M}\right\}=\arg \max \zeta\left(a_{i}, a_{j}\right)$.

\footnotetext{
${ }^{5}$ I address the impact of the sex ratio in Section 3.6 below.
} 
The couple's output $\zeta_{i j}=\zeta\left(a_{i}, a_{j}\right)$ can be divided between the spouses and the utility of each partner is linear in the share he $\backslash$ she receives. This reflects transferable utility between the spouses. The material surplus of the marriage is then defined as

$$
z_{i j} \equiv \zeta\left(a_{i}, a_{j}\right)-\zeta_{m}-\zeta_{w}
$$

There are two kinds of partnership and two possible modes of equilibrium household behavior regarding how $a_{i}$ and $a_{j}$ are chosen. In particular, couples can cohabitate or marry. And conditional on their marital status, the couples take the actions $a_{i}$ and $a_{j}$. By definition, these actions are taken non-cooperatively and without commitment in cohabitation. But, in marriage, they can be taken cooperatively and with some level of marital commitment.

Let a man $i$ be represented by $I(i)$, where $I(i)=M$ if $i$ is willing to make a potentially costly commitment to his marriage and $I(i)=N$ if he is not. And let woman $j$ be denoted by $J(j)$, where $J(j)=M$ if $j$ is willing to marry and commit and $J(j)=N$ if she is not. Let $U_{j}$ and $V_{i}$ respectively denote the material allocations of woman $j$ and man $i$ respectively.

We can now define the kinds of household partnership and modes of action as follows:

Definition 2 (Cohabitation): Man $i$ and woman $j$ can cohabitate which does not require any commitment or coordination. A cohabiting man $i$ solves

$$
\max _{a_{i}} V_{N}\left(a_{i}, a_{j}^{N}\right)=\max _{a_{i}}\left[\zeta\left(a_{i}, a_{j}^{N}\right)-\zeta_{m}-\zeta_{w}-U_{j}\left(a_{i}, a_{j}^{N}\right)\right] \quad \text { s.t. } U_{N}+V_{N} \leq z_{N N}
$$

and a cohabiting woman $j$ solves

$$
\max _{a_{j}} U_{N}\left(a_{i}^{N}, a_{j}\right)=\max _{a_{i}}\left[\zeta\left(a_{i}^{N}, a_{j}\right)-\zeta_{m}-\zeta_{w}-V_{i}\left(a_{i}^{N}, a_{j}\right)\right] \text { s.t. } U_{N}+V_{N} \leq z_{N N}
$$

where, by definition, $a_{i}^{N}$ represents the Nash best response to $a_{j}^{N}$ and vice versa. The Nash-Cournot material output $\zeta\left(a_{i}^{N}, a_{j}^{N}\right) \equiv \zeta_{N N}$ is such that, $\forall a_{i}^{N} \neq a_{i}^{M}$, and $a_{j}^{N} \neq$ $a_{j}^{M}, \zeta_{N N}<\zeta_{M M}$ and $a_{i}^{N}=\arg \max V_{N}\left(a_{i}, a_{j}^{N}\right) \equiv V^{N}$ and $a_{j}^{N}=\arg \max U_{N}\left(a_{i}^{N}, a_{j}\right)$ $\equiv U^{N}$. 
Definition 3 (Marriage): Man $i$ and woman $j$ can marry. In marriage, they can choose $a_{i}, a_{j}$ with or without commitment:

1. (Commitment) Committed married couples take the actions $a_{i}^{M}, a_{j}^{M}$. In doing so, they recognize that $\zeta_{i j}=\zeta_{M M} \equiv \zeta\left(a_{i}^{M}, a_{j}^{M}\right)$ and $U_{j}=U_{M}, V_{i}=V_{M}$, where $U_{M}$ and $V_{M}$ represent the endogenously determined shadow prices of committed husbands and committed wives (which are determined below).

2. (No Commitment) Uncommitted married couples behave as cohabiting couples do. Hence, they choose $a_{i}^{N}=\arg \max V_{N}\left(a_{i}, a_{j}^{N}\right) \equiv V^{N}$ and $a_{j}^{N}=\arg \max$ $U_{N}\left(a_{i}^{N}, a_{j}\right) \equiv U^{N}$.

We now need to specify the outcome of the partnership of a committed and an uncommitted individual. In such a mixed match, the committed spouse would be willing to marry and choose the action that maximizes the material surplus $\left(a_{i}^{M}\right.$ or $a_{j}^{M}$ ) while the uncommitted spouse would maximize only his own material utility subject to his spouse's participation constraint. Let the behavior of uncommitted partners be defined as "opportunistic" when they are paired up with committed spouses, with $a_{i}^{O}$ and $a_{j}^{O}$ representing the actions commensurate with "opportunistic" mode of action by man $i$ and woman $j$, respectively. Letting the material output of a committed husband $i$ and an opportunistic wife $j$ equal $\zeta_{M O} \equiv \zeta\left(a_{i}^{M}, a_{j}^{O}\right)$ and that of an opportunistic husband $i$ and a committed wife $j$ be defined as $\zeta_{O M} \equiv \zeta\left(a_{i}^{O}\right.$, $\left.a_{j}^{M}\right)$, we introduce the following definition:

Definition 4 (Opportunistic Marital Behavior): When husband $i$ is not committed to the efficient choices in his marriage but his wife $j$ is,

$$
V_{i}\left(a_{i}^{O}, a_{j}^{M}\right)=\zeta_{O M}-\zeta_{m}-\zeta_{w} \equiv z_{O M} \quad \text { and } \quad U_{j}\left(a_{i}^{O}, a_{j}^{M}\right)=0
$$

and when husband $i$ is committed but wife $j$ is not,

$$
U_{j}\left(a_{i}^{M}, a_{j}^{O}\right)=\zeta_{M O}-\zeta_{m}-\zeta_{w} \equiv z_{M O} \quad \text { and } \quad V_{i}\left(a_{i}^{M}, a_{j}^{O}\right)=0
$$


In words, when they are married to a committed spouse, uncommitted individuals act opportunistically and extract all of their marital surplus. This leads to the following important observation:

Lemma 5 In equilibrium, no spouse can behave opportunistically. Mixed-couples resort to a Nash-Cournot game and all spouses in such marriages receive $U^{N}$ and $V^{N}$.

Proof. $\forall I(i)=M \wedge J(j)=O, V_{i}\left(a_{i}^{M}, a_{j}^{O}\right)=0<V^{N}$ and $\forall I(i)=O \wedge J(j)=M$, $U_{i}\left(a_{i}^{O}, a_{j}^{M}\right)=0<U^{N}$. Thus, $\forall I(i)=M \wedge J(j)=O, a_{i}=a_{i}^{N}=\arg \max V_{i}\left(a_{i}, a_{j}^{O}\right)$. Likewise, $\forall I(i)=O \wedge J(j)=M, a_{j}=a_{j}^{N}=\arg \max U_{j}\left(a_{i}^{O}, a_{j}\right)$. As a result, $\forall I(i)$ $=M \wedge J(j)=O, z i j=z_{N N}, U_{j}=U^{N} \wedge V_{i}=V^{N}$. And, $\forall I(i)=O \wedge J(j)=M$, $z i j=z_{N N}, U_{j}=U^{N} \wedge V_{i}=V^{N}$.

Consequently, when a committed partner marries an uncommitted one, they generate the output $\zeta_{M N}=\zeta_{N M}=\zeta_{N N}$ and the surplus $z_{M N}=z_{N M}=z_{N N}$. Since cooperation yields a Pareto efficient outcome for all married couples who can commit and cooperate, it follows that

$$
z_{M M}+z_{N N}>z_{N M}+z_{M N}=2 z_{N N}
$$

Hence, marital surplus rises with the commitment level of both partners.

There are two parameters in this model which influence the desire of men and women to marry or cohabitate, and if they prefer to marry, whether or not they would be able to act with commitment. First, commitment to a marriage (and, by extension, a spouse) is costly. It involves idiosyncratic non-pecuniary costs denoted by $\mu_{i}$ for men and $\mu_{j}$ for women. Once an individual decides to maritally commit and takes a course of action accordingly, these $\mu$ 's become sunk costs and dissolving the union would not reimburse the cost of spousal commitment. Two common examples such costly commitment are (i) specialization within the household by market and nonmarket time use; and (ii) the decision to have children, which might require differential time involvement by gender and spouse. For example, having children might require one spouse to withdraw from the labor market and a prolonged period of labor force detachment could hurt his/her future wages (Korenman and Neumark, 1992). The important aspect of such commitment costs is that they are either non-pecuniary 
in nature, such as the social stigma or approval associated with being a maritally committed spouse. Or, as the examples above indicate, these costs are pecuniary but of a specific nature such that the action taken could erode the reservation utility level or the outside option of the committed spouse. ${ }^{6}$

Second, individuals derive non-material gains from marriage which I denote by $\theta_{i}$ and $\theta_{j}$ for man $i$ and woman $j$. The $\theta$ 's represent the non-material personal gains from marriage that are above and beyond the satisfaction of cohabiting with someone. And one can view the $\theta$ 's as the non-pecuniary cost of marriage for each individual, especially if legal marriage is viewed as more inhibiting or (emotionally) costlier to dissolve in case either or both individuals want a separation. ${ }^{7}$

These idiosyncratic cost and preference parameters are assumed to be independent of each other and across individuals. I denote the distributions of $\theta$ and $\mu$ by $F(\theta)$ and $G(\mu)$ for men and by $\hat{F}(\theta)$ and $\hat{G}(\mu)$ for women, respectively. All four distributions are symmetric around their means. ${ }^{8}$

We can now define the total partnership surplus (including the material and non-

\footnotetext{
${ }^{6}$ Note, however, an important distinction that I make here: typically, all choices that involve marital public goods or spousal specialization influence the material resources of the household and such choices might involve personal material costs to each spouse as well. Clearly, all such material costs are embedded in the couples' material output discussed above. As such, the non-material cost of commitment, $\mu$, represents the additional utility costs to the person of marital commitment. The idea is that, due to innate differences or family backgrounds, some men and women find it more easy to commit to marital decisions and choices than others - whatever the material cost of such choices might be (as reflected in the couples' material production).

${ }^{7}$ Generally, one could also factor in individuals' preferences for being in a partnership and account for the idiosyncratic non-material gains one can accrue from having a household partner relative to being single. In that case, even the equilibrium with an equal sex ratio could involve some individuals who prefer to remain single as well. The rest of the analysis, however, would remain unaltered.

More to the point, the existence of singles in equilibrium on either side of the market would not affect intra-household allocations in any kind of partnership mode. This is because, as we shall see below, the influence on intra-marital spousal allocations in committed marriages mainly derive from the competition of those who would be on the margins of marriage without commitment and cohabitation. For this reason, I have chosen to abstract from this angle.

${ }^{8} \mathrm{By}$ construction, the individual costs and benefits are observable at the time of marriage to both spouses. If the costs and benefits are not directly observable, then the results discussed below would still go through unaltered if individuals act on the basis of noisy but unbiased signals. If, instead, the decision to marry and commit is made on the basis of expected costs and benefits, the main results would still attain but the derivations would become cumbersome.
} 
material components) generated by the marriage of $i$ and $j$ as

$$
s_{i j}= \begin{cases}z_{N N} & \text { if }\{i, j\} \text { cohabit, } \\ z_{N N}+\theta_{i}+\theta_{j} & \text { if }\{i, j\} \text { marry without commitment } \\ z_{M M}+\theta_{i}+\theta_{j}-\mu_{i}-\mu_{j} & \text { if }\{i, j\} \text { marry with commitment. }\end{cases}
$$

It is imperative to clarify the difference between cohabitation and marriage without commitment, or why making such a distinction is even warranted. Clearly, cohabitation and marriage without spousal commitment are indistinguishable from each other in terms of the element of commitment involved - none - and the material partnership payoffs. Whether or not individuals prefer marriage without commitment over cohabitation is, thus, purely driven by their perceived net cost (or benefit) of being in the legal marriage state. As we shall see below shortly, this suggests that there are essentially two pools of individuals from which the maritally committed spouses could be drawn, with two margins being important for becoming a maritally committed spouse: Among those who have a relatively high preference for being legally married, the only important parameter would be the burden of commitment. And even among those who would otherwise choose cohabitation over legal marriage, there would be individuals whose commitment costs would be low enough for them to consider marriage with commitment as a viable alternative.

\subsection{The Matching Market}

Each individual who is willing to marry or cohabitate has perfect substitutes in the matching markets. Upon this basis, one can identify the spousal allocations within committed marriages. ${ }^{9}$ In effect, the matching process provides us with shadow prices for men and women, where the price of each individual is determined not only by his or her preferences and costs, but also by those of other available mates.

\footnotetext{
${ }^{9}$ According to Definitions 2 and 3, intra-household allocations in cohabitation and marriages without commitment are determined by a noncooperative Nash-Cournot mechanism. Hence, market forces in general and the supply of or the demand for partners with different propensities have no bearing on allocations in such relationships.
} 
The Stable Assignment Profiles: Any stable assignment of men to women must maximize the aggregate surplus over all possible assignments (Shapley and Shubik, 1972). The dual of this linear programming problem posits the existence of nonnegative shadow prices associated with the constraints of the primal that each person can be either single or matched with one spouse. Accordingly, the complementarity slackness conditions require

$$
s_{i j} \leq v_{i}+u_{j}
$$

Condition (4) yields

$$
v_{i}=\max \left\{\max _{j}\left(s_{i j}-u_{j}\right), 0\right\} \quad \text { and } \quad u_{j}=\max \left\{\max _{i}\left(s_{i j}-v_{i}\right), 0\right\},
$$

which means that the assignment problem can be decentralized. That is, given the shadow prices $u_{j}$ and $v_{i}$ (which by definition are the shares of man $i$ and woman $j$ in the partnership surplus), each agent matches with a spouse that yields the highest "profit" or remains single. Alternatively, we can view the shadow prices $u_{j}$ and $v_{i}$ as the reservation utility levels that woman $j$ and man $i$ require to participate in any partnership of marriage or cohabitation.

With this specification, we have a convenient structure in which the interactions between agents depend on their marital preferences and commitment costs only. In particular, we can write the endogenously-determined shadow prices of married man $i$ and woman $j$ in the following forms:

$$
v_{i}=\max \left(\hat{V}_{i}, 0\right) \text { and } u_{j}=\max \left(\hat{U}_{j}, 0\right)
$$

where

$$
\hat{V}_{i} \equiv \begin{cases}V_{I} & \text { if } I(i)=N \& i \text { cohabits, } \\ V_{I}+\theta_{i} & \text { if } I(i)=N \& i \text { marries } \\ V_{I}+\theta_{i}-\mu_{i} & \text { if } I(i)=M,\end{cases}
$$

and

$$
\hat{U}_{j} \equiv \begin{cases}U_{J} & \text { if } J(j)=N \& j \text { cohabits } \\ U_{J}+\theta_{i} & \text { if } J(j)=N \& j \text { marries } \\ U_{J}+\theta_{i}-\mu_{i} & \text { if } J(j)=M,\end{cases}
$$


and where, given Definitions 2 and $3, V_{I}$ and $U_{J}$ are the shares that the partners receive from the material surplus of the match (not accounting for the idiosyncratic preferences $\theta_{i}$ and $\theta_{j}$ and the costs of commitment $\mu_{i}$ and $\mu_{j}$ ). Assuming that at least one person in each class is matched with a partner, this implies that

$$
V_{I}=\max _{J}\left[z_{I J}-U_{J}\right] \quad \text { and } \quad U_{J}=\max _{I}\left[z_{I J}-V_{I}\right]
$$

All agents receive the same share of the material surplus $z_{I J}$ no matter with whom they are matched. And any man (woman) can be fully characterized by his or her pair of $(\theta, \mu)$. Consider a person who would be willing to marry and commit to a particular spouse: No such mate could ask for a higher share than his "going rate" because he could be replaced by an equivalent alternative.

Stability Conditions: Although, in equilibrium, there are equal numbers of men and women who are matched with a mate (either in marriage or cohabitation), it is possible that the equilibrium numbers of men and women who prefer marriage over cohabitation or those who can marry with commitment would differ. Under the assumption that all equilibria sustain cohabitation as well as marriages with commitment, we have

$$
\begin{aligned}
& U_{M}+V_{M}=z_{M M}, \\
& U_{N}+V_{N}=z_{N N} .
\end{aligned}
$$

The marital shares of committed wives, $U_{M}$, and husbands, $V_{M}$, are yet to be determined. But those of uncommitted married couples or cohabiting couples are pinned down by Definition 2, according to which we have the Nash-Cournot outcomes of $U_{N}=U^{N}$ and $V_{N}=V^{N}$.

On this basis, we can classify the possible matching patterns as follows: Under pure assortative mating, the number of men who want to marry and commit equals women who'd like to do the same. And the number of men who'd like to cohabit equals those of women who prefer the same. In this case, only equations (8) and (9) hold.

Next, consider these additional restrictions:

$$
U_{N}+V_{M} \geq z_{M N},
$$




$$
U_{M}+V_{N} \geq z_{N M}
$$

If, among the married, there are more men who are willing to commit to their marriages than women, some committed men will marry uncommitted women and condition (10) will hold with a strict equality. But if there are more committed women than men among the married, then (11) will apply with a strict equality.

When, in addition to equations (8) and (9), either (10) or (11) holds as a strictly equality as well, then there exists a mixed sorting equilibrium. In a mixed assortative equilibrium, there are either more men than women who would like to marry with commitment or the other way around, but not both. It is impossible that both conditions will hold as equalities because, together with (8) and (9), this would imply

$$
z_{M M}+z_{N N}=z_{N M}+z_{M N}=2 z_{N N} \quad \Rightarrow \quad z_{M M}=z_{N N}
$$

which violates assumption (2) that the commitment levels of the spouses are complements, i.e., $z_{M M}>z_{N N}$. Thus, either committed men marry uncommitted women or committed women marry uncommitted men but not both.

Moreover, according to Lemma 5, we have $z_{M N}=z_{N N}, U_{N}=U^{N}$ and $V_{M}=V^{N}$ in equation (10) and $z_{N M}=z_{N N}, U_{M}=U^{N}$ and $V_{N}=V^{N}$ in equation (11). Thus, when types mix and there are more committed men than committed women among the married, there are some marriages between uncommitted women and committed men in equilibrium. In those marriages, couples resort to a Nash-Cournot game so that Lemma 5 holds and equations (8), (9) and (10) evaluated as a strict equality generate

$$
U_{M}-U_{N}=z_{M M}-z_{N N}, \quad \text { and } \quad V_{M}-V_{N}=0
$$

In words, when uncommitted women marry committed men, then the former can take advantage of the latter to extract all of the material surplus. As a result, some men who would otherwise be willing to commit to their marriages would be forced to resort to the Nash-Cournot non-cooperative behavior in their marriages to uncommitted women. Since some committed men are still lucky enough to marry committed women, men compete for committed women up to the point where $V_{M}=$ $V_{N}=V^{N}$. This in turn generates the maximum marital return for committed women which equals $U_{M}=z_{M M}-z_{N N}$.

If there are more committed women then men among the married, then there are some marriages between uncommitted men and committed women in equilibrium. In 
those marriages, $U_{M}=U_{N}=U^{N}$. Together with conditions (8), (9) and (11) holding as a strict equality, this yields

$$
V_{M}-V_{N}=z_{M M}-z_{N N}, \quad \text { and } \quad U_{M}-U_{N}=0 .
$$

Thus, when there are more committed women than men in the marriage market, committed men extract all of their marital surplus.

The main point here is that the differences $U_{M}-U_{N}$ and $V_{M}-V_{N}$ represent the return to marital commitment for women and men, respectively. ${ }^{10}$ Consider the case of women, for instance: The quantity $z_{M M}-z_{N N}$, which reflects the return a committed woman earns in the marriage market when such women are in short supply, defines the upper bound on the return to commitment in marriage, whereas her return which vanishes when her type is on the long side of the market defines the lower bound. The essential observation is that women receive their upper bound in a mixed equilibrium with more men willing to commit to their marriages than women who are willing to do so. But committed women who prefer marriage get no marital surplus if the mixed equilibrium involves more women willing to commit to their marriages than men.

Proposition 6 (a) In the pure-sorting, fully symmetric equilibrium, $U_{M}=V_{M}=$ $z_{M M} / 2$ and $U_{N}=V_{N}=z_{N N} / 2$ with $U_{M}=V_{M}>U_{N}=V_{N}$; (b) In a mixed-marriage equilibrium with women who prefer committed marriages are short supply, $V_{M}=V_{N}$ $=V^{N}, U_{N}=U^{N}$ and $U_{M}=z_{M M}-V^{N}$ with $U_{M}>V_{M}$; (c) In the mixed-marriage market equilibrium with committed men in short supply, $U_{M}=U_{N}=U^{N}, V_{N}=V^{N}$ and $V_{M}=z_{M M}-U^{N}$ with $V_{M}>U_{M}$.

Proof. (a) When the model is completely symmetric, $U^{N}=V^{N}$, and $\forall \theta, F(\theta)=$ $\hat{F}(\theta), \forall \mu, G(\mu)=\hat{G}(\mu)$. Then, only (8) and (9) hold as equalities and (5) yields equal shares for all spouses; (b) Follows directly from (8), (9), and (11) holding as a strict equality; (c) Follows directly from (8), (9), and (10) holding as a strict equality.

An important issue is whether some of the "gross material shares" defined above, $U_{J}$ and $V_{I}$, can be non-positive in equilibrium. In particular, if couples can exchange

\footnotetext{
${ }^{10}$ Since the material allocations $V_{I}$ and $U_{J}$ split the output of man $i$ and woman $j$, these marital commitment returns are in part based on with whom man $i$ and woman $j$ are matched.
} 
and transfer "signs of endearment", then the material shares can be negative in equilibrium when the non-material utility from marriage is relatively high. But note that the Nash-Cournot outcome rules out non-negative material spousal allocations. That is, in all equilibria, $U_{N}=U^{N}>0$ and $V_{N}=V^{N}>0$. In addition, I prove in Appendix section 6.1 that $U_{M} \geqslant U_{N}$ and $V_{M} \geqslant V_{N}$. Hence, all material equilibrium allocations in this model are strictly positive.

On this basis, everyone prefers living in a marriage or cohabitation partnership over staying single. ${ }^{11}$ And as long as the sex ratio equals unity, all men and women would enter the matching market to find a partner with whom they can either cohabitate or marry with or without commitment.

\subsection{Optimal Partnership Modes}

I assume rational expectations so that, in equilibrium, individuals know $V_{I}$ and $U_{J}$ which, together with the costs of commitment and the non-economic gains of marriage, are sufficient statistics for the individuals decision to commit to the ex-ante spousal allocations or try to renege on them once they marry. Given these shares, the knowledge of their own idiosyncratic preferences for marriage, $\theta$, and costs of commitment, $\mu$, agents know for sure whether they will marry, and if they do marry, whether they will credibly commit to the ex-ante expected spousal allocations, $V_{M}$ and $U_{M}$, dictated by the marriage market.

In particular, man $i$ prefers marriage over cohabitation if $\theta_{i}>0$, and he chooses marriage with commitment over everything else if

$$
\zeta_{m}+V_{M}+\theta_{i}-\mu_{i}>\zeta_{m}+\max \left(V_{N}, V_{N}+\theta_{i}\right)
$$

Similarly, woman $j$ prefers marriage over cohabitation if $\theta_{j}>0$, and she chooses marriage with commitment over everything else if

$$
\zeta_{w}+U_{M}+\theta_{j}-\mu_{j}>\zeta_{w}+\max \left(U_{N}, U_{N}+\theta_{j}\right)
$$

The LHS of the inequalities in (15) and (16) represent the total utility individuals $i$ and $j$ get when they are committed in marriage and the RHS of the two equations

\footnotetext{
${ }^{11}$ See footnote 7 .
} 
represent their utility when they are not, which holds when $i$ or $j$ are involved in either a marriage without commitment or a cohabitation.

Proposition 7 (1.a) Men for whom $\theta \leq 0$ and $\left(V_{M}-V_{N}\right)+\theta \leq \mu$ only cohabitate; (1.b) Men for whom $\theta>0$ and $\mu \geqslant V_{M}-V_{N}$ marry without commitment; (1.c) Men for whom $\theta>0$ and $\mu<V_{M}-V_{N}$ as well as men for whom $\theta \leq 0$ and $\left(V_{M}-\right.$ $\left.V_{N}\right)+\theta>\mu$ marry with commitment. (2.a) Women for whom $\theta \leq 0$ and $\theta \leq$ $\mu-\left(U_{M}-U_{N}\right)$ only cohabitate; (2.b) Women for whom $\theta>0$ and $\mu \geqslant U_{M}-U_{N}$ marry without commitment; (2.c) Women for whom $\theta>0$ and $\mu<U_{M}-U_{N}$ marry with commitment.

Proof. The material returns of a noncommittal marriage and cohabitation are identical; they are either $U^{N}$ or $V^{N}$. Hence, the non-material gain of marriage, $\theta$, solely determines if $i$ or $j$ prefers marriage without commitment over cohabitation. For $\theta>0$, being married provides an extra non-material gain and marriage dominates cohabitation. Appendix 6.1 shows all material shares are non-negative and $V_{N} \leq V_{M}$ and $U_{N} \leq U_{M}$. If $\theta>0$ and $\mu \geqslant\left(V_{M}-V_{N}\right)$, the RHS of (15) strictly exceeds its LHS and man $i$ prefers marriage over cohabitation and marriage without commitment to marriage with it. In contrast, if $\theta>0$ and $\mu<\left(V_{M}-V_{N}\right)$ or if $\theta \leq 0$ and $\left(V_{M}-V_{N}\right)+\theta>\mu$, then the LHS of (15) strictly exceeds its RHS and man $i$ prefers marriage over cohabitation and marriage with commitment to marriage without it. Same arguments analogously hold for women.

Figure 1 describes the choices made by different men, taking as given those made by women. The upward-sloping bold line represents $\mu=\theta+\left(V_{M}-V_{N}\right)$, which delineates the region of commitment in marriage from cohabitation. All combinations of $\theta$ and $\mu$ to the right of the upward-sloping line represent men who prefer to marry with commitment and all those to the left of the upward-sloping line apply to men who choose to enter a noncommittal relationship. In quadrants II and III, cohabitation is preferable over marriage without commitment and in quadrants I and IV the opposite holds. Consequently, all combinations of $\theta$ and $\mu$ in the II, III quadrants and above and to the left of the $\mu=\theta+\left(V_{M}-V_{N}\right)$ locus generate cohabitation; all combinations of $\theta$ and $\mu$ in the I, IV quadrants and above and to the left of the $\mu=\theta+\left(V_{M}-V_{N}\right)$ locus generate marriage without commitment. For the remainder of the analysis, 
I assume that the variability in $\theta$ and $\mu$ are large enough to ensure that all three regions are always non-empty in equilibrium.

Figure 1 reveals the fundamental issues involved in making the choice among the three modes of partnership. As I alluded to before, there are two different pools of men from which the maritally committed husbands could be drawn: Among those who have a relatively high preference for being legally married - those with high $\theta$ 's the only important parameter is the burden of marital commitment: For these men, the choice of legal marriage over cohabitation is not in doubt. And a low enough $\mu$ is the only thing that matters for these men to decide whether they want to be a committed husband or a non-committed one (essentially shifting them from quadrant I to IV). Among those with a high cost of or low preference for marriage, however, both $\theta$ and $\mu$ come into play. Provided that the preference for cohabitation is not too high, a sufficiently low commitment cost would be enough to entice these individuals to consider marriage with commitment as a viable alternative to cohabitation (moving them from quadrant III to IV).

[Figure 1 about here.]

Given equations (15) and (16) and the distributions of $\theta$ and $\mu$, the proportion of men who marry and credibly commit to cooperate is

$$
\frac{G\left(V_{M}-V_{N}\right)}{2}+\int_{-\infty}^{0} G\left(V_{M}-V_{N}+\theta\right) f(\theta) d \theta
$$

and the proportion of all men who marry is

$$
\frac{1}{2}+\int_{-\infty}^{0} G\left(V_{M}-V_{N}+\theta\right) f(\theta) d \theta
$$

The first term in equation (18) includes all men who marry and cannot commit as well as some of those who marry and commit, i.e., men for whom $\theta>0$ and $\mu \geqslant$ $V_{M}-V_{N}$ as well as those for whom $\theta>0$ and $\mu<V_{M}-V_{N}$. The second term in that equation covers those who get married with commitment because they possess $\theta \leq 0$ and $\left(V_{M}-V_{N}\right)+\theta>\mu$. 
Obviously, the higher is the gross return to commitment in marriage, $V_{M}$, the higher is the proportion of men who marry and commit. And the higher is the gross return to cohabitation, $V_{N}$, the higher is the proportion of men who cohabit or marry without commitment. It is also the case that more men who seek a committed relationship would raise the numbers of men who want to marry as well as commit.

\subsection{Equilibrium}

If the equilibrium involves pure sorting on the basis of marriage, cohabitation and commitment, then the numbers of men and women who marry and credibly commit will be the same. Using condition (17), we can derive this condition as

$\frac{G\left(V_{M}-V_{N}\right)}{2}+\int_{-\infty}^{0} G\left(V_{M}-V_{N}+\theta\right) f(\theta) d \theta=\frac{\hat{G}\left(U_{M}-U_{N}\right)}{2}+\int_{-\infty}^{0} \hat{G}\left(U_{M}-U_{N}+\theta\right) \hat{f}(\theta) d \theta$.

Since, by Proposition 6 we have $V_{N}=U_{N}=z_{N N} / 2$, equations (8) and (19) yield a system of two equations in two unknowns. That is, (8) and (19) yield unique solutions for $V_{M}$ and $U_{M}$. If a feasible solution exists, then there will be equal numbers of men and women in the marriage markets who can commit. As a result, we will have a pure sorting equilibrium in which some married couples are in committed relationships and all cohabiting couples, by construction, aren't. And while cohabiting couples play a Nash-Cournot game in order to determine their household allocations, married couples make household decisions in a fully cooperative manner.

If there is some mixing of types, equation (19) is replaced by an inequality and the shares $U_{M}$ and $V_{M}$ are determined by the boundary conditions on the returns to marital commitment for either men or women, whichever is applicable. If there are more committed men than women among those who wish to marry, then (19) evaluated at $U_{M}=z_{M M}-V^{N}$ and $V_{M}=V_{N}=V^{N}$, will produce

$$
\frac{G(0)}{2}+\int_{-\infty}^{0} G(\theta) f(\theta) d \theta>\frac{\hat{G}\left(z_{M M}-z_{N N}\right)}{2}+\int_{-\infty}^{0} \hat{G}\left(z_{M M}-z_{N N}+\theta\right) \hat{f}(\theta) d \theta .
$$

As a result, we'll have a mixed equilibrium in which some men who wish to commit marry women who prefer not to, with all such couples resorting to a Nash-Cournot 
mechanism.

Conversely, if there are more committed women than men among the married, (19) evaluated at $V_{M}=z_{M M}-U^{N}$ and $U_{M}=U_{N}=U^{N}$, yields

$$
\frac{G\left(z_{M M}-z_{N N}\right)}{2}+\int_{-\infty}^{0} G\left(z_{M M}-z_{N N}+\theta\right) f(\theta) d \theta<\frac{\hat{G}(0)}{2}+\int_{-\infty}^{0} \hat{G}(\theta) \hat{f}(\theta) d \theta
$$

Now we'll have a mixed equilibrium in which some women who wish to commit marry men who prefer not to, with all such couples resorting to a Nash-Cournot game.

By adding the numbers of men and women who want to marry without commitment to both sides of (19), we can establish when the aggregate demand for marriage equals aggregate supply on both sides of the market:

$$
\int_{-\infty}^{0} G\left(V_{M}-V_{N}+\theta\right) f(\theta) d \theta .=\int_{-\infty}^{0} \hat{G}\left(U_{M}-U_{N}+\theta\right) \hat{f}(\theta) d \theta
$$

As with equation (19), (20) need not hold in equilibrium. In fact, all four combinations are possible, with both (19) and (20) holding as strict equalities, neither (19) nor (20) being satisfied, and only (19) or (20) holding in equilibrium. Clearly, both (19) and (20) need to hold in a pure sorting equilibrium but (19) won't hold in a mixed assortative equilibrium, in which case there is excess demand for marital commitment on either side of the matching market, and (20) won't be satisfied in an equilibrium where there is excess demand for marriage either among the men or women.

To elaborate a little further, the Nash-Cournot payoffs, $U^{N}$ and $V^{N}$, are invariant to changes in the matching market conditions. Thus, whether or not (19) or (20) holds as a strict equality depends on whether the market adjustments in $U_{M}$ and $V_{M}$ suffice the clear the excess demand for marriage and marital commitment. Of course, that is precisely the case when the model is completely symmetric so that, $U^{N}=$ $V^{N}$, and $\forall \theta, F(\theta)=\hat{F}(\theta), \forall \mu, G(\mu)=\hat{G}(\mu)$, which together yield a strictly interior solution such that $V_{M} \in\left[V^{N}, z_{M M}\right]$ and $U_{M} \in\left[U^{N}, z_{M M}\right]$. For heuristic purposes and without loss of generality, I shall assume hereafter that in a purely symmetric and gender neutral case, $V_{M}=U_{M}=z_{M M} / 2$. 
I depict all possible equilibria in Figures 2 through 4 . In all of the figures, I depict the equilibrium conditions given by (19) and (20) in terms of $V_{N}$ and $V_{M}$ after eliminating $U_{N}$ and $U_{M}$ using (8) and (9). The upward-sloping lines define equations (19) and (20); they represent the combinations of $V_{M}$ and $V_{N}$ that maintain equality in the numbers of men and women who wish to marry and in the numbers of men and women who marry and commit to cooperate. There is no reason for these loci to overlap as they are drawn, although in a model of complete symmetry they will overlap with the two market clearing loci collapsing onto each other. These lines slope upward with a 45 degree angle because a one unit increase in the return to cohabitation or marriage without commitment, $V_{N}$, would necessitate an equal rise in the return to marriage with commitment, $V_{M}$, in order to restore the equilibrium between the numbers of men and women who prefer marriage generally and marriage with commitment.

The vertical line marks the Nash-Cournot payoff to men in cohabitation or noncommittal marriage, which equals $z_{N N} / 2$. Due to the fact that this payoff does not respond to changes in the matching market conditions, all possible equilibria will involve this level of $V_{N}=V^{N}=z_{N N} / 2$. The lower horizontal line represents the case defined by equation (10) according to which the excess supply of men who prefer marriage with commitment drive their return to commitment in marriage to its lower bound of $V_{M}=V^{N}=z_{N N} / 2$. The upper horizontal line, in contrast, defines the opposite case defined by equation (11), whereby the shortage of men who prefer marriage with commitment drive their return in a committed marriage to its upper bound of $V_{M}=z_{M M}-z_{N N} / 2$.

As long as the model is completely symmetric, that is $U^{N}=V^{N}$ and, $\forall \theta, F(\theta)=$ $\hat{F}(\theta), \forall \mu, G(\mu)=\hat{G}(\mu)$, the equilibrium is characterized by equal sharing: $V_{M}=$ $U_{M}=z_{M M} / 2$ and $U_{N}=U^{N}=V_{N}=V^{N}=z_{N N} / 2$. With these shares, men and women have identical commitment incentives. Hence, the number of men who can credibly commit to marriage equals the number of women who can do so. Such a solution is described by point $e$ in Figure 2, where the line satisfying (19) and (20) intersects the vertical line for $V_{N}=V^{N}=z_{N N} / 2$ strictly within the upper and lower bounds of the $V_{M}$ payoff. In this case, there is a unique symmetric equilibrium. Maritally committed men and women share their marital surplus equally, so that $U_{M}$ $=V_{M}=z_{M M} / 2$. Uncommitted married couples as well as cohabiting ones play the 
Nash-Cournot game in which, due to perfect symmetry, each spouse chooses the same course of action and we get $U_{N}=U^{N}=V_{N}=V^{N}=z_{N N} / 2$.

Even when we have a pure-sorting equilibrium, there may be a shortage of men or women who prefer to maritally commit when $V_{M}=U_{M}=z_{M M} / 2$, because $U^{N}$ and $V^{N}$ do not adjust for (19) to hold. In that case, $V_{M}$ and $U_{M}$ will adjust away from $z_{M M} / 2$ in order to clear the market for maritally committed men and women. In Figure 3, I depict a pure-sorting equilibrium in which, at point $e$, there is a shortage of men who are willing to maritally commit. Thus, the upward sloping line that represents (19) and (20) will shift up so that $V_{M}$ will adjust upward until (19) starts to hold once again. The new equilibrium point $e^{\prime}$ lies above $e$ and on the unique interior value of $V_{M}$.

[Figures 2 and 3 about here.]

With further changes in the distributions of $\theta$ and $\mu$, the two lines representing (19) and (20) will shift up or down. For moderate levels of asymmetry, the intersection of the upward-sloping line representing (19) and (20) continues to intersect the vertical $V_{N}=V^{N}=z_{N N} / 2$ locus on the interior of the value of $V_{M}$. In all such scenarios, the equilibrium still involves pure sorting on the basis of marital commitment. But with greater asymmetry in the model, the equilibrium will become mixed, because (19) will no longer hold in the range $\left[z_{N N} / 2, z_{M M}-z_{N N} / 2\right]$. That is, when either $F(\theta)$ stochastically dominates $\hat{F}(\theta)$ and $\hat{G}(\mu)$ dominates $G(\mu)$ or $\hat{F}(\theta)$ stochastically dominates $F(\theta)$ and $G(\mu)$ dominates $\hat{G}(\mu)$, there may be a mixed equilibrium where either condition (19.a) or (19.b) will hold. Such a case is illustrated by the point $e^{\prime \prime}$ in Figure 4. In this equilibrium, maritally committed men obtain the upper bound on their return to marital commitment, $V_{M}=z_{M M}-z_{N N} / 2$ and uncommitted married men or cohabiting ones get $V_{N}=z_{N N} / 2$. The equilibrium point $e^{\prime \prime}$ is given by these combinations of unique $V_{M}$ and $V_{N}$. In this equilibrium, there is a shortage of men who can maritally commit and some mixed marriages in which some women prefer committed marriages in non-committal marriages and others who prefer marriage ended up in cohabitation.

[Figures 3 and 4 about here.] 
Proposition 8 (1) A pure-sorting equilibrium with equal numbers of maritally committed men and women requires complete symmetry so that $U^{N}=V^{N}$ and $\forall \theta$, $F(\theta)=\hat{F}(\theta) \wedge \forall \mu, G(\mu)=\hat{G}(\mu)$; it is fully characterized by (8), (9), (19) and (20); and it generates $V_{M}=U_{M}=z_{M M} / 2$ and $V_{N}=U_{N}=z_{N N} / 2$;

(2) A mixed equilibrium with a surplus of maritally-committed men requires $F(\theta)$ to stochastically dominate $\hat{F}(\theta)$ and/or $\hat{G}(\mu)$ to dominate $G(\mu)$ such that (19.a) holds with $V_{M}=V^{N}$ and $U_{M}=z_{M M}-V^{N}$; this equilibrium is fully characterized by (8), (9), (10) and (19.a);

(3) A mixed equilibrium with a shortage of maritally-committed men requires $\hat{F}(\theta)$ to stochastically dominate $F(\theta)$ and/or $G(\mu)$ to dominate $\hat{G}(\mu)$ such that (19.b) holds with $U_{M}=U^{N}$ and $V_{M}=z_{M M}-U^{N}$; it is fully characterized by (8), (9), (11) and (19.b).

Proof. See Appendix Section 6.2.

In sum, when there is an excess supply of maritally-committed women in the matching market, the return to marital commitment for all men rises. This creates higher incentives for men to maritally commit to ex-ante marital allocations determined in the matching stage despite the fact that the distributions for marriage preference and costs of commitment yield higher costs and lower marriage preference among the men. Also, some men or women who would like to marry but not commit in marriage may have to settle to cohabit with someone, because they would be bumped down by those women who prefer to maritally commit who cannot do so due to a lack of like minded men. As a result, regardless of whether the equilibrium is mixed or pure, there can be an excess supply of men or women who would like to marry in the aggregate.

\subsection{Impact of an Unequal Sex Ratio}

Although I assumed thus far that there are equal numbers of men and women in the population, one can easily extend the analysis to examine the impact of an uneven sex ratio. Let $r \gtreqless 1$ represent the ratio of men to women in the population. Then, we modify equations (19) and (20) as follows, respectively: 


$$
\begin{gathered}
r\left[\frac{G\left(V_{M}-V_{N}\right)}{2}+\int_{-\infty}^{0} G\left(V_{M}-V_{N}+\theta\right) f(\theta) d \theta\right] \\
= \\
\frac{\hat{G}\left(U_{M}-U_{N}\right)}{2}+\int_{-\infty}^{0} \hat{G}\left(U_{M}-U_{N}+\theta\right) \hat{f}(\theta) d \theta,
\end{gathered}
$$

and

$$
r \int_{-\infty}^{0} G\left(V_{M}-V_{N}+\theta\right) f(\theta) d \theta .=\int_{-\infty}^{0} \hat{G}\left(U_{M}-U_{N}+\theta\right) \hat{f}(\theta) d \theta .
$$

Note that, even if $U^{N}=V^{N}$ and, $\forall \theta, F(\theta)=\hat{F}(\theta), \forall \mu, G(\mu)=\hat{G}(\mu)$, the equilibrium with an uneven sex ratio may not be characterized by equal sharing. For example, if $r>1$ and there are more men than women in the population, then both $\left(19^{\prime}\right)$ and $\left(20^{\prime}\right)$ imply that $V_{M}$ will need to decline and $U_{M}$ will need to rise to ensure that there are equal numbers of men and women who can maritally commit and equal numbers of men and women who prefer marriage in both its forms. As a result, the return for marital commitment of the sex in excess supply will fall and that of the sex in short supply will rise, regardless of whether the matching market equilibrium is strict or mixed.

For $r$ closer to unity, equation (19') may still continue to hold and a pure sorting equilibrium with equal numbers of men and women who want to marry and commit emerging. However, with more uneven sex ratios, equation $\left(19^{\prime}\right)$ may not hold even if $U^{N}=V^{N}$ and, $\forall \theta, F(\theta)=\hat{F}(\theta), \forall \mu, G(\mu)=\hat{G}(\mu)$. Then, there will be a mixed equilibrium in which some men who want to marry with commitment match with women who don't. Whether there will be equal numbers of men and women in total in the marriage market will be independent of market clearing among the committed spouses and $\left(20^{\prime}\right)$ may fail to hold even in a pure-sorting equilibrium. However, ceteris paribus, increases (decreases) in $r$ would tend to create an excess supply of both committed and uncommitted men (women) in the matching market. Consequently, increases in the sex ratio $r$ would make it more likely that the RHS of both equations $\left(19^{\prime}\right)$ and $\left(20^{\prime}\right)$ exceed the LHS. 
In Figure 5, I depict the impact of a rise in the sex ratio. The figure is drawn under the assumption that the market is completely symmetric initially; $U_{M}=V_{M}=z_{M M / 2}$, $U^{N}=V^{N}$ and, $\forall \theta, F(\theta)=\hat{F}(\theta), \forall \mu, G(\mu)=\hat{G}(\mu)$. Thus, when the sex ratio $r$ equals one, we have the pure-sorting equilibrium with matching market clearing in the aggregate depicted in Figure 2; that is, there are equal numbers of men and women who wish to marry, among whom there are also equal numbers of men and women willing to commit to the ex-ante marriage prices. When the sex ratio $r$ rises above one, then $\left(19^{\prime}\right)$ implies that $V_{M}$ will need to drop and $U_{M}$ will need to rise to compensate women who wish to marry with commitment for the increase in the number of men who are willing to commit to cooperative behavior. As a result, the upward-sloping line which represents market clearing among the committed individuals will need to shift lower. However, given that $V_{N}$ and $U_{N}$ are determined by non-cooperative NashCournot behavior, they will not adjust with changes in $r$. For moderate changes in $r$, the equilibrium will still yield pure sorting so that $\left(19^{\prime}\right)$ still attains. As shown in Figure 5, there will be equal numbers of committed men and women in the marriage market, but due to higher $r$, the former will get a smaller share of the marital surplus. In aggregate, there will be a higher number of men who would like to marry but cannot commit than the number of women who would like to do the same.

[Figure 5 about here.]

Lemma 9 With an uneven sex ratio, $r \neq 1$, a mixed equilibrium can be attained even if $U^{N}=V^{N}$ and $\forall \theta, \mu, F(\theta)=\hat{F}(\theta), G(\mu)=\hat{G}(\mu)$.

Proof. Follows immediately from Proposition 8 and equations $\left(19^{\prime}\right)$ and $\left(20^{\prime}\right)$.

\section{An Example}

Consider the following simple example to trace the model's main implications: Assume that, irrespective of the differences in labor market wages or household roles, 
men and women have the same preferences given by

$$
u=v= \begin{cases}c q & \text { if individual } i \text { or } j \text { is single or cohabiting, } \\ c q+\theta & \text { if individual } i \text { or } j \text { is married but not committed } \\ c q+\theta-\mu & \text { if individual } i \text { or } j \text { is married and committed }\end{cases}
$$

where $c$ is a private good, $q$ is a public good that can be shared if two people marry but is private if they remain single.

The household public good is produced according to a production function

$$
q=t
$$

where $t$ represents time spent in home production. This specification reflects transferable utility between spouses, and the fact that the public good $q$ can be shared in a partnership is what generates a surplus in marriage or cohabitation.

All individuals are endowed with one unit of time. The wage rate for all men is identical and equal to $w^{m}$ and that for all women is identical and equal to $w^{w}$ with $w^{m}>w^{w}$.

\subsection{Marriage with Spousal Commitment}

If two mates who wish to marry \& commit match with each other in a pure-sorting equilibrium, they maximize

$$
\max _{q, c_{i}+c_{j}} u_{j}+v_{i}=q\left(c_{i}+c_{j}\right)+\theta_{i}+\theta_{j}-\mu_{i}-\mu_{j}
$$

subject to (22) and their budget constraint

$$
c_{i}+c_{j} \leq w^{m}\left(1-t_{i}\right)+w^{w}\left(1-t_{j}\right) .
$$

The efficient household division of labor then involves the husband specializing in market work $\left(t_{i}=0\right)$ and the wife undertaking home production $\left(t_{j}=1\right)$ so that the maximized material output is

$$
\left(c_{i}+c_{j}\right) q=w^{m} \equiv \zeta_{M M} .
$$


In contrast, a single man $i$ solves

$$
\underset{q_{i}, c_{i}}{\operatorname{Max}} c_{i} q_{i}
$$

subject to $q_{i}=t_{i}$ and

$$
c_{i} \leq w^{m}\left(1-t_{i}\right)
$$

His optimal behavior generates a utility level of $\zeta_{m}=w^{m} / 4$. A single woman $j$ solves an analogous problem and obtains $\zeta_{w}=w^{w} / 4$. Therefore, the total marital surplus generated by a cooperative marriage mode is

$$
s_{i j} \equiv z_{M M}+\theta_{i}+\theta_{j}-\mu_{i}-\mu_{j}=\frac{3 w^{m}-w^{w}}{4}+\theta_{i}+\theta_{j}-\mu_{i}-\mu_{j},
$$

Due to the fact that the equilibrium involves pure sorting, we get $U_{M}=V_{M}=$ $z_{M M} / 2=\left(3 w^{m}-w^{w}\right) / 8$.

\subsection{The Nash-Cournot Outcome}

Next consider a couple who prefer to cohabitate or marry without commitment in a pure-sorting equilibrium. Each partner or spouse in such a match recognizes that his or her partner is not willing to abide by the ex-ante agreement regarding spousal roles and allocations. Instead, each partner maximizes his or her own utility given by (21) subject to (22), (27) and taking as given his/her spouses' choices. That is, such a man $i$ matched with a woman $j$ solves

$$
\max _{q, c_{i}} \begin{cases}c_{i} q & \text { if }\{i, j\} \text { cohabit } \\ c_{i} q+\theta_{i} & \text { if }\{i, j\} \text { marry without commitment }\end{cases}
$$

subject to equations (22), (27), and

$$
q=t_{i}+\bar{t}_{j}
$$

Woman $j$ solves an analogous problem and the optimal time allocation of the couple $(i, j)$ yields $t_{i}=t_{j}=1 / 3$. Consequently, $U_{N}=U^{N}=7 w^{w} / 36, \zeta_{m}+U_{N}=$ $4 w^{w} / 9, V_{N}=V^{N}=7 w^{m} / 36$, and $\zeta_{w}+V_{N}=4 w^{m} / 9$.

The maximized material output of the couple is

$$
\left(c_{i}+c_{j}\right) q=\frac{4\left(w^{m}+w^{w}\right)}{9} \equiv \zeta_{N N} .
$$


The total surplus generated by this match is then given by

$$
s_{i j}=\frac{7\left(w^{m}+w^{w}\right)}{36}+\theta_{i}+\theta_{j} \equiv z_{N N}+\theta_{i}+\theta_{j} .
$$

\subsection{Opportunistic Marital Behavior}

In mixed-sorting equilibria, either committed men match with uncommitted women or uncommitted men match with committed women. Consider first the combination of a committed woman $j$ and an uncommitted man $i$, and the scenario in which $j$ abides by her commitment. Since $w^{m}>w^{w}$, woman $j$ would supply all of the home production time $\left(t_{j}=1\right)$ but man $i$, given that he is not willing to commit, would maximize his private consumption taking as given his wife's full-time commitment. That is, man $i$ would solve

$$
\operatorname{Max}_{t_{i}, c_{i}} c_{i} q+\theta_{i}
$$

subject to

$$
\begin{gathered}
c_{i}+c_{j}=\left(1-t_{i}\right) w^{m}, \\
q=t_{i}+1,
\end{gathered}
$$

and

$$
\zeta_{w}=\frac{w^{w}}{4} \wedge U_{M}=0 \Rightarrow c_{j}=\frac{w^{w}}{4\left(t_{i}+1\right)} .
$$

As a result, we get $t_{i}=0, c_{j}=w^{w} / 4$ and $c_{i}=w^{m}-w^{w} / 4$, which yield $V_{N}=$ $z_{N M}$, and $\zeta_{m}+V_{N}=\zeta_{m}+z_{N M}$, with the total partnership surplus generated by the marriage now being equal to

$$
s_{i j}=\frac{3 w^{m}-w^{w}}{4}+\theta_{i}+\theta_{j}-\mu_{j} \equiv z_{N M}+\theta_{i}+\theta_{j}-\mu_{j} .
$$

Similarly, when a committed man $i$ and an uncommitted woman $j$ get married in a mixed equilibrium and man $i$ is willing to remain committed, woman $j$ chooses $t_{j}$ in order to maximize her own utility taking as given $\bar{t}_{i}=0$ : 


$$
\underset{q, c_{j}}{\operatorname{Max}} c_{j} q+\theta_{j}
$$

subject to

$$
\begin{gathered}
c_{i}+c_{j} \leq w^{m}, \\
q=t_{j},
\end{gathered}
$$

and

$$
\zeta_{m}=\frac{w^{m}}{4} \wedge V_{M}=0 \Rightarrow c_{i}=\frac{w^{m}}{4 t_{j}} .
$$

This problem generates $t_{j}=1, c_{i}=w^{m} / 4$, and $c_{j}=3 w^{m} / 4$. As a result, we have, $\zeta_{m}+V_{M}=\zeta_{m}=\gamma w^{m} / 4$ and $\zeta_{w}+U_{N}=\zeta_{w}+z_{M N}$.

The total partnership surplus now equals

$$
s_{i j}=\frac{3 w^{m}-w^{w}}{4}+\theta_{i}+\theta_{j}-\mu_{j} \equiv z_{M N}+\theta_{i}+\theta_{j}-\mu_{i} .
$$

Note that $z_{M M}=z_{N M}=z_{M N}>z_{N N}$ but in both kinds of marriage either $U_{M}=$ 0 or $V_{M}=0$. Thus, neither of the two outcomes defined above are sustainable and both couples will revert to Nash-Cournot defined by (29) through (32). ${ }^{12}$

\subsection{Equilibrium}

Next, consider uniform distributions of $\theta$ and $\mu$ such that they respectively have $[-a$, $a]$ and $[-b, b]$ as their supports of the lower and upper bounds, where. Under strictly positive assortative mating, the numbers of men and women who are willing to marry and commit are equal. Then, according to (19)

${ }^{12}$ From equations (28) and (32) we get

$$
z_{M M}+z_{N N}=\frac{3 w^{m}-w^{w}}{4}+\frac{7\left(w^{m}+w^{w}\right)}{36}=\frac{17 w^{m}-w^{w}}{18}
$$

and

$$
z_{M N}+z_{N M}=2 z_{N N}=\frac{7\left(w^{m}+w^{w}\right)}{18} .
$$

Hence, $z_{M M}+z_{N N}>z_{M N}+z_{N M}$ and positive sorting equilibria holds. 


$$
\begin{gathered}
\frac{V_{M}-V_{N}+b}{4 b}+\frac{\left(V_{M}-V_{N}+b\right)^{2}-\left(V_{M}-V_{N}-a+b\right)^{2}}{8 a b} \\
= \\
\frac{U_{M}-U_{N}+b}{4 b}+\frac{\left(U_{M}-U_{N}+b\right)^{2}-\left(U_{M}-U_{N}-a+b\right)^{2}}{8 a b} .
\end{gathered}
$$

Equation (19.c) simplifies to $V_{M}-V_{N}=U_{M}-U_{N}$ and, given the identical distributions of $\theta$ and $\mu$, along with the fact that $U_{N}=U^{N}=7 w^{w} / 36$ and $V_{N}=V^{N}=$ $7 w^{m} / 36$, it is clear that (19.c) will hold if and only if $V_{M}-U_{M}=7\left(w^{m}-w^{w}\right) / 36$.

For the numbers of men and women who wish to marry with or without commitment to be equal, we need

$$
\frac{\left(V_{M}-V_{N}+b\right)^{2}-\left(V_{M}-V_{N}-a+b\right)^{2}}{8 a b}=\frac{\left(U_{M}-U_{N}+b\right)^{2}-\left(U_{M}-U_{N}-a+b\right)^{2}}{8 a b} .
$$

which also reduces to $V_{M}-V_{N}=U_{M}-U_{N}$. Equation (20.c) will also hold if and only if $V_{M}-U_{M}=7\left(w^{m}-w^{w}\right) / 36$.

Thus, if $V_{M}=\left(17 w^{m}-8 w^{w}\right) / 36$ and $U_{M}=\left(10 w^{m}-w^{w}\right) / 36$ both (19.c) and (20.c) are satisfied. With that, we get a pure sorting equilibrium in which a fraction of all marriages involve cooperative and committed behavior and the rest of the marriages as well as all cohabiting couples are characterized by non-cooperative Nash-Cournot outcome outcomes. And as (19.c) indicates, the higher are the gains from marriage, the wider is the distribution of $\theta \mathrm{s}$, and the narrower that of $\mu$, the higher is the fraction of marriages in which spouses commit and behave cooperatively.

With $V_{M}=\left(17 w^{m}-8 w^{w}\right) / 36$ and $U_{M}=\left(10 w^{m}-w^{w}\right) / 36$, the proportion of committed men and women in the matching market equals

$$
\frac{b}{4}+\frac{5 w^{m}-4 w^{w}}{72}
$$

and the fraction of all men and women (both committed and uncommitted) in the matching market equals

$$
\frac{a^{2} b\left(5 w^{m}-4 w^{w}-9 a+18 b\right)}{1152} .
$$

Equations (17.a) and (18.a) then define a pure-sorting equilibrium such as the one depicted in Figure 3. 
For heuristic purposes, now take the case in which the distributions of $\mu$ differ by gender so that for men we have $[-b, b+\delta], 0<\delta$, and for women we still have $[-b, b]$, as the supports of the lower and upper bounds of $\mu$. Under strictly positive assortative mating, the numbers of men and women who are willing to marry and commit are equal. Then, (19) generates

$$
\begin{gathered}
\frac{V_{M}-V_{N}+b}{4 b+2 \delta}+\frac{\left(V_{M}-V_{N}+b\right)^{2}-\left(V_{M}-V_{N}-a+b\right)^{2}}{8 a b+4 a \delta} \\
= \\
\frac{U_{M}-U_{N}+b}{4 b}+\frac{\left(U_{M}-U_{N}+b\right)^{2}-\left(U_{M}-U_{N}-a+b\right)^{2}}{8 a b} .
\end{gathered}
$$

For the numbers of men and women who are on the marriage market to be equal, we need

$$
\frac{\left(V_{M}-V_{N}+b\right)^{2}-\left(V_{M}-V_{N}-a+b\right)^{2}}{8 a b+4 a \delta}=\frac{\left(U_{M}-U_{N}+b\right)^{2}-\left(U_{M}-U_{N}-a+b\right)^{2}}{8 a b} .
$$

For $\delta$ close to zero, the analysis above would still hold and a pure sorting equilibrium would continue to be sustained. With higher $\delta$, men become more reluctant to marry and commit. As a consequence, $V_{M}$ will rise and $U_{M}$ will fall in order to keep (20.d) satisfied. However, with sufficiently large $\delta,(20 . \mathrm{d})$ will no longer be satisfied evaluated at the upper bound of $V_{M}=z_{M M}-U^{N}$ and $U_{M}=U^{N}$. Hence, we find that if men's distribution of commitment costs significantly dominate that for women in a first-order stochastic sense, then there will be more women willing to commit and marry than men but also more total women than men who would like to marry with or without commitment. Consequently, some women who would like to be in a committed marriage would have to marry without commitment and some other women who would like to marry without commitment would have to cohabitate in equilibrium.

\section{Conclusion}

More couples cohabitate now in industrialized countries than they did three decades ago and the propensity to marry has shown a commensurate decline. The general con- 
sensus among economists is that cohabitation is an imperfect substitute for marriage, typically exhibiting a lower level of commitment. Beyond that, however, existing work on how commitment factors in marriage versus cohabitation has been relatively scant, with no acknowledgment that spousal commitment levels could vary across married couples too, and how the trends in marriage, cohabitation as well as spousal commitment ought to coevolve.

If marriage and cohabitation are substitutes and the choice of marital commitment could not be taken for granted, then it is important to identify the conditions under which some couples choose to marry and act cooperatively, while others decide to marry with a lower level of commitment or simply cohabitate, mostly refraining from a commitment to a longer-term relationship. Such a quest requires a unified framework according to which marriage and cohabitation as well as cooperative and non-cooperative spousal behavior can coexist in equilibrium and individuals choose not only their (desired) marital status but their optimal modes of behavior.

In this paper, I presented a model of marriage versus cohabitation and marital commitment versus limited commitment in determining intra-household choices and allocations. On that basis, I showed that some married couples are able to cooperate and operate efficiently, but some married and all cohabiting couples act with limited commitment and non-cooperatively. When spousal marital commitment costs are gender symmetric, there is a pure-sorting equilibrium in which all partners who prefer to act with commitment in marriage are matched with someone who has the same preference. In such an equilibrium, the benefits of marital commitment accrue to both partners.

But when there is a mixed matching equilibrium with, say, committed husbands in short supply, men's marital commitment incentives will be higher because committed women compete more intensely for committed husbands. An excess supply of men who prefer marriage not only reduces the marriage incentives of men and raises those of women, but also the marital commitment incentives of men. In such mixedmatching equilibria, the benefits of marital commitment accrue only those men or women who are in short supply and a shortage of men (women) who can maritally commit makes all women (men) worse off and materially indifferent between marriage or cohabitation. Finally, we saw that, if the gains from marriage fall, then not only would more individuals choose to cohabitate but more married couples would act 
non-cooperatively.

An essential insight which emerged from all this is that allocations and outcomes in uncommitted partnerships could, for the most part, be unresponsive to market forces. Nevertheless, the degree to which the institution of legal marriage manifests spousal commitment and cooperation is driven by individual attitudes toward cohabitation, marriage as well as spousal commitment as those are manifested in market dynamics. 


\section{Appendix}

\subsection{Proving that $V_{M} \geqslant V_{N}$ and $U_{M} \geqslant U_{N}$ :}

- If there is a mixed equilibrium with more committed men than committed women, we have $V_{M}=V_{N}=V^{N}, U_{N}=U^{N}$, and $U_{M}=z_{M M}-V^{N}$. Since $z_{M M}$ $>z_{N N}, U_{N}+V_{N}=U^{N}+V^{N}=z_{N N} \Rightarrow U_{N}=z_{N N}-V^{N}$, it follows that $U_{M}$ $=z_{M M}-V^{N}>U_{N}$. Hence, $V_{M}=V_{N}$ and $U_{M}>U_{N}$.

- If there is a mixed equilibrium with more committed women than committed men, $U_{M}=U_{N}=U^{N}, V_{N}=V^{N}$, and $V_{M}=z_{M M}-U^{N}$. Since $z_{M M}>z_{N N}$, $U_{N}+V_{N}=U^{N}+V^{N}=z_{N N} \Rightarrow V_{N}=z_{N N}-U^{N}$, it follows that $V_{M}=z_{M M}$ $-U^{N}>V_{N}$. Hence, $U_{M}=U_{N}$ and $V_{M}>V_{N}$.

- If there is a pure-sorting equilibrium, then only (9) and (10) hold so that $U_{N}$ $+V_{N}=U^{N}+V^{N}=z_{N N}$ and $U_{M}+V_{M}=z_{M M}$. Given (2), $z_{M M}>z_{N N}$. Moreover, stability in the matching markets, together with spousal commitment to efficient outcomes, suggests no committed spouse can be worse off materially than he or she could be in another marriage. Thus, either $V_{M} \geqslant V_{N}$ and $U_{M}>$ $U_{N}$, or $V_{M}>V_{N}$ and $U_{M} \geqslant U_{N}$, or $V_{M}>V_{N}$ and $U_{M}>U_{N}$

\subsection{Proof of Proposition 8:}

- (1) If $U^{N}=V^{N}$ and, $\forall \theta, F(\theta)=\hat{F}(\theta) \wedge \forall \mu, G(\mu)=\hat{G}(\mu)$, then (19) holds with $V_{M}=U_{M}=z_{M M} / 2$ and $(20)$ holds with $V_{M}=U_{M}=z_{M M} / 2$ and $V_{N}=$ $U_{N}=z_{N N} / 2$. As a result, there are equal numbers of men and women who want to marry with commitment as well as equals numbers of total men and women in the marriage market. Consequently, equations (8), (9), (19) and (20) define a pure-sorting equilibrium in which $V_{M}=U_{M}=z_{M M} / 2$ and $V_{N}=U_{N}=$ $z_{N N} / 2$;

- (2) If $F(\theta)$ stochastically dominates $\hat{F}(\theta)$ and/or $\hat{G}(\mu)$ dominates $G(\mu)$, then (19) evaluated at $V_{M}=U_{M}=z_{M M} / 2$ generates 


$$
\begin{aligned}
& \frac{1}{2} G\left(\frac{z_{M M}-z_{N N}}{2}\right)+\int_{-\infty}^{\infty} G\left(\frac{z_{M M}-z_{N N}}{2}+\theta\right) f(\theta) d \theta \\
& \frac{1}{2} \hat{G}\left(\frac{z_{M M}-z_{N N}}{2}\right)+\int_{-\infty}^{\infty} \hat{G}\left(\frac{z_{M M}-z_{N N}}{2}+\theta\right) \hat{f}(\theta) d \theta .
\end{aligned}
$$

Given $F(\theta), \hat{F}(\theta), \hat{G}(\mu)$ and $G(\mu)$, if $\nexists V_{M} \in\left(V^{N}, z_{M M} / 2\right] \wedge U_{M} \in\left[z_{M M} / 2, z_{M M}-\right.$ $V^{N}$ ), then (19) cannot hold in equilibrium but (19.a) will. If (19.a) holds, then $V_{M}$ $=V^{N}$ and $U_{M}=z_{M M}-V^{N}$. As a result, (8), (9) and (10), together with (19.a), fully characterize this mixed equilibrium, in which there are more men than women who would want to marry with commitment.

- (3) If $\hat{F}(\theta)$ to stochastically dominates $F(\theta)$ and/or $G(\mu)$ to dominates $\hat{G}(\mu)$, then (19) evaluated at $V_{M}=U_{M}=z_{M M} / 2$ generates

$$
\begin{aligned}
& \frac{1}{2} G\left(\frac{z_{M M}-z_{N N}}{2}\right)+\int_{-\infty}^{\infty} G\left(\frac{z_{M M}-z_{N N}}{2}+\theta\right) f(\theta) d \theta \\
& < \\
& \frac{1}{2} \hat{G}\left(\frac{z_{M M}-z_{N N}}{2}\right)+\int_{-\infty}^{\infty} \hat{G}\left(\frac{z_{M M}-z_{N N}}{2}+\theta\right) \hat{f}(\theta) d \theta .
\end{aligned}
$$

Given $F(\theta), \hat{F}(\theta), \hat{G}(\mu)$ and $G(\mu)$, if $\nexists U_{M} \in\left(U^{N}, z_{M M} / 2\right] \wedge V_{M} \in\left[z_{M M} / 2\right.$, $\left.z_{M M}-U^{N}\right)$, then (19) cannot hold in equilibrium but (19.b) will. If (19.b) holds, then $U_{M}=U^{N}$ and $V_{M}=z_{M M}-U^{N}$. As a result, (8), (9) and (10), together with (19.b), fully characterize this equilibrium with more women than men who would like to marry with commitment. 


\section{References}

[1] Aguiar, M. and E. Hurst (2006). "Measuring Trends in Leisure: The Allocation of Time over Five Decades," Federal Reserve Bank of Boston Working Paper No. 06-2.

[2] Baker, M. J. and J. P. Jacobsen. (2003). "Marriage, Specialization, and the Gender Division of Labor," University of Connecticut, unpublished manuscript.

[3] Becker, G. S. (1981). A Treatise on the Family, (MA: Harvard University Press).

[4] Bourguignon, F. and P. Chiappori. (1994). "The Collective Approach to Household Behavior," in R. Blundell, I. Preston, and I. Walker eds., The Measurement of Household Welfare, (Cambridge, U.K.: Cambridge University Press).

[5] Browning, M. (2009). "Love, Betrayal and Commitment," Oxford University, unpublished manuscript.

[6] Browning, M., F. Bourguignon, P. A. Chiappori, and V. Lechene. (1994). "Income and Outcomes: A Structural Model of Intra-household Allocation," Journal of Political Economy, 102 (6), 1067-96.

[7] Browning, M., P. A. Chiappori, and V. Lechene. (2004). "Collective and Unitary Models: a Clarification," Oxford University, unpublished manuscript.

[8] Browning, M., P. A. Chiappori, and Y. Weiss. (2003). "A Simple Matching Model of the Marriage Market," University of Chicago, unpublished manuscript.

[9] Browning, M., P. A. Chiappori, and Y. Weiss. (in progress). Family Economics, (Cambridge, UK: Oxford University Press).

[10] Chen, Z. and F. Woolley. (2001). "A Cournot-Nash Model of Family Decisionmaking," Economic Journal, 111 (474), 722-48.

[11] Chiappori, P. A. (1988). "Rational Household Labor Supply," Econometrica, 56, 63-90. 
[12] Chiappori, P. A. (1992). "Collective Labor Supply and Welfare," Journal of Political Economy, 100 (3), 437-67.

[13] Chiappori, P. A. (1997). "Introducing Household Production in Collective Models of Labor Supply," Journal of Political Economy, 105, 191-209.

[14] Chiappori, P. A., B. Fortin, and G. Lacroix. (2002). "Marriage Market, Divorce Legislation, and Household Labor Supply," Journal of Political Economy, $110(1), 37-72$.

[15] Chiappori, P. A. and Y. Weiss. (2000). "Marriage Contracts and Divorce: An Equilibrium Analysis," University of Chicago, unpublished manuscript.

[16] Chiappori, P. A. and Y. Weiss. (2004). "Divorce, Remarriage and Child Support," Tel Aviv University, unpublished manuscript.

[17] Chiappori, P. A. M. Iyigun and Y. Weiss. (forthcoming). "Investment in Schooling and the Marriage Market," American Economic Review.

[18] Chiappori, P. A. M. Iyigun and Y. Weiss. (2008). "An Assignment Model with Divorce and Remarriage," IZA Working Paper No: 3892, December.

[19] Del Boca, D. and C. Flinn. (2005). "Household Time Allocation and Modes of Behavior: A Theory of Sorts," New York University, unpublished manuscript.

[20] Daniel, K. (1992). "Does Marriage Make Men More Productive?," Economic research Center (NORC), Working Paper Series, No: 92-2.

[21] Gemici, A. and S. Laufer. (2009). "Marriage and Cohabitation," New York University, unpublished manuscript.

[22] Gronau, R. (1986). "Home Production-a Survey" in O. Ashenfelter and R. Layard, eds., Handbook of Labor Economics, Volume 1A, (Amsterdam: NorthHolland).

[23] Hadfield, G. K. (1999). "A Coordination Model of the Sexual Division of Labor," Journal of Economic Behavior and Organization, 40 (2), 125-53. 
[24] Iyigun, M. and R. P. Walsh. (2007a). "Endogenous Gender Power, Labor Supply, and the Quantity-Quality Tradeoff," Journal of Development Economics, 82:1, January, 138-55.

[25] Iyigun, M. and R. Walsh. (2007b). "Building the Family Nest: Pre-Marital Investments, Marriage Markets and Spousal Allocations," Review of Economic Studies, 74:2, April, 507-35.

[26] Korenman, S. and D. Neumark. (1992). "Marriage, Motherhood, and Wages," Journal of Human Resources, 27, 233-55.

[27] Lundberg, S. and R. A. Pollak. (1993). "Separate Spheres Bargaining and the Marriage Market," Journal of Political Economy, 101 (6), 988-1010.

[28] Lundberg, S. and R. A. Pollak. (2003). "Efficiency in Marriage," Review of Economics of the Household, September.

[29] Lundberg, S. and R. A. Pollak. (2009). "Marriage Market Equilibrium and Bargaining", University of Washington at Saint Louis, unpublished manuscript.

[30] Lundberg, S., R. A. Pollak, and T. J. Wales. (1997). "Do Husbands and Wives Pool Their Resources?," Journal of Human Resources, 32 (3), 31-44.

[31] Manser, M. and M. Brown. (1980). "Marriage and Household DecisionMaking: A Bargaining Analysis," International Economic Review, 21, February, $31-44$.

[32] Matouschek, N. and I. Rasul. (2008). "The Economics of the Marriage Contract: Theories and Evidence," Journal of Law \& Economics, vol. 51, February.

[33] Mazzocco, M. (2007). "Household Intertemporal Behavior: a Collective Characterization and a Test of Commitment," Review of Economic Studies, Vol. 74, No. 3, July pp. 857-895.

[34] McElroy, M. B. and M. J. Horney. (1981). "Nash-Bargained Decisions: Towards a Generalization of the Theory of Demand," International Economic Review, 22, June, 333-49. 
[35] Peters, M. and A. Siow. (2002). "Competing Pre-Marital Investments," Journal of Political Economy, 110 (3), 592-608.

[36] Rasul, I. (2005). "Household Bargaining over Fertility: Theory and Evidence from Malaysia," University College London, unpublished manuscript.

[37] Samuelson, P. (1956). "Social Indifference Curves," Quarterly Journal of Economics, 70 (1), 1-22.

[38] Sen, A. (1983). "Economics and the Family," Asian Development Review, 1, 14-26.

[39] Udry, C. (1996). "Gender, the Theory of Production, and the Agricultural Household," Journal of Political Economy, 104 (5), October, 1010-46.

[40] Weiss, Y. (1997). "The Formation and Dissolution of Families: Why Marry? Who Marries Whom? And What Happens in Divorce?" in M. Rosenzweig and O. Stark, eds. Handbook of Population and Family Economics, Volume 1A, (Amsterdam: Elsevier Publishers).

[41] Wells, R. and M. Maher. (1998). "Time and Surplus Allocation Within Marriage," Massachusetts Institute of Technology, unpublished mimeo. 
Figure 1: Marital Choices and Commitment Decisions of Men

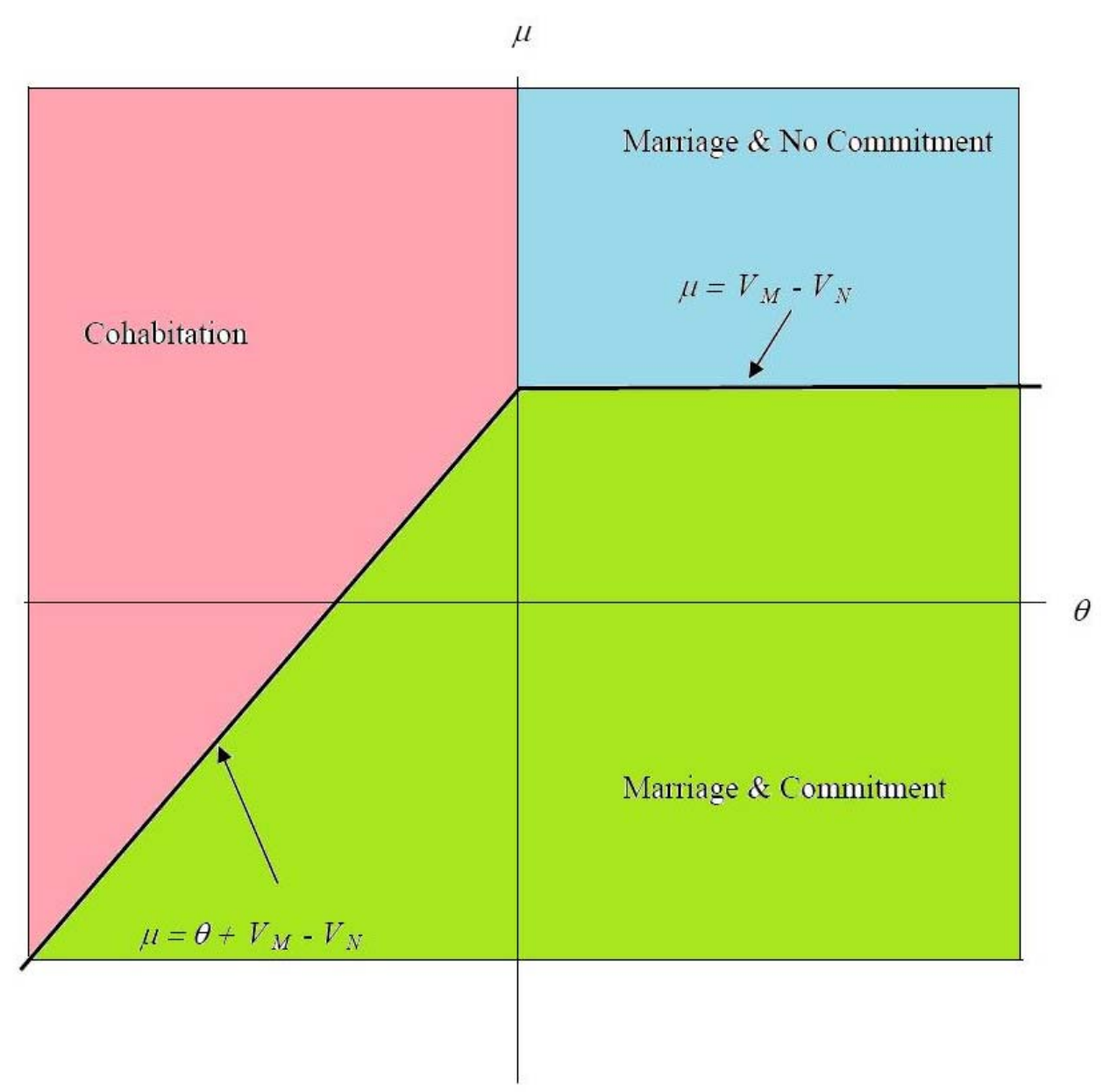


Figure 2: A Pure-Sorting Equilibrium with Aggregate Market Clearing

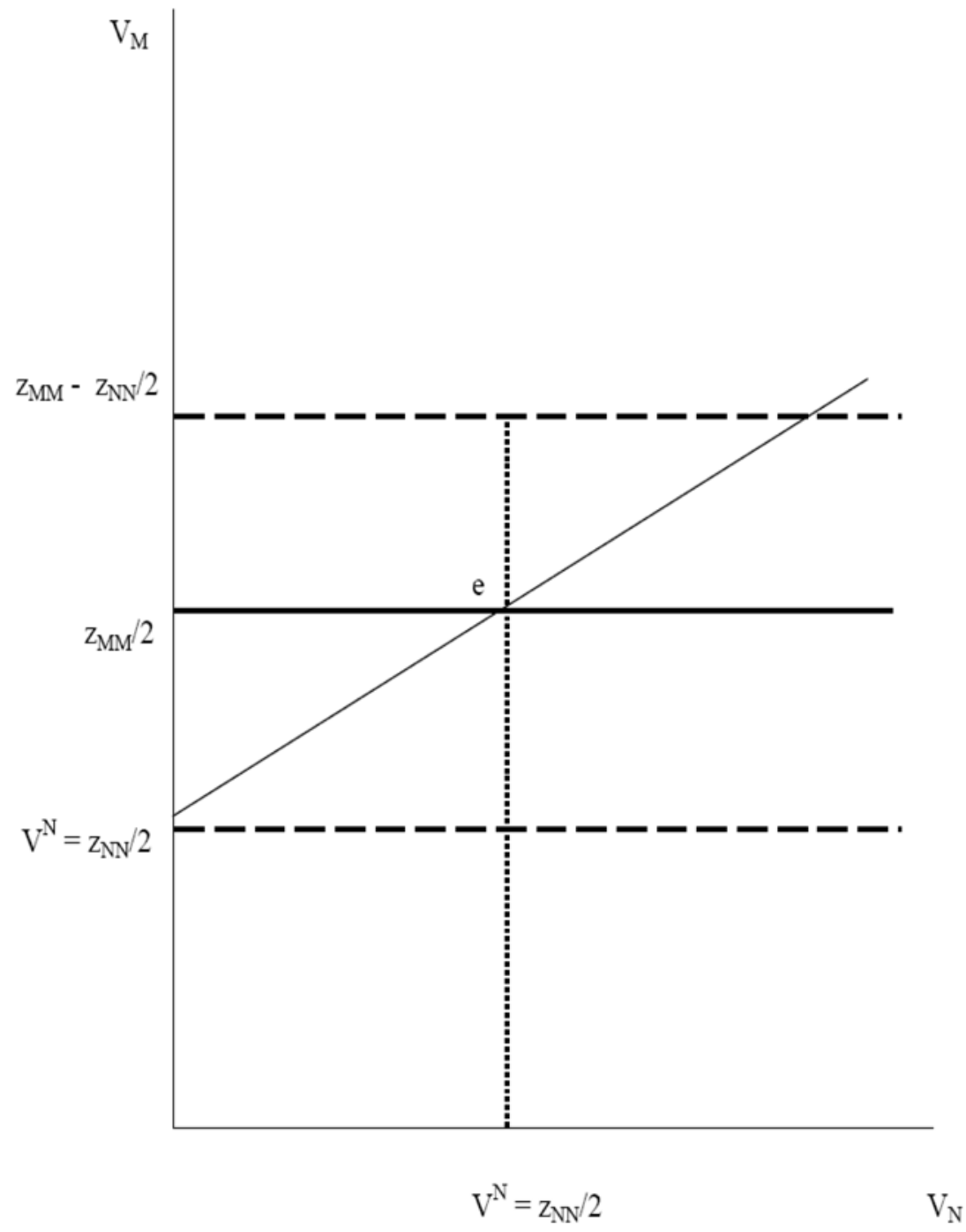


Figure 3: A Pure-Sorting Equilibrium with a Shortage of Committed Men

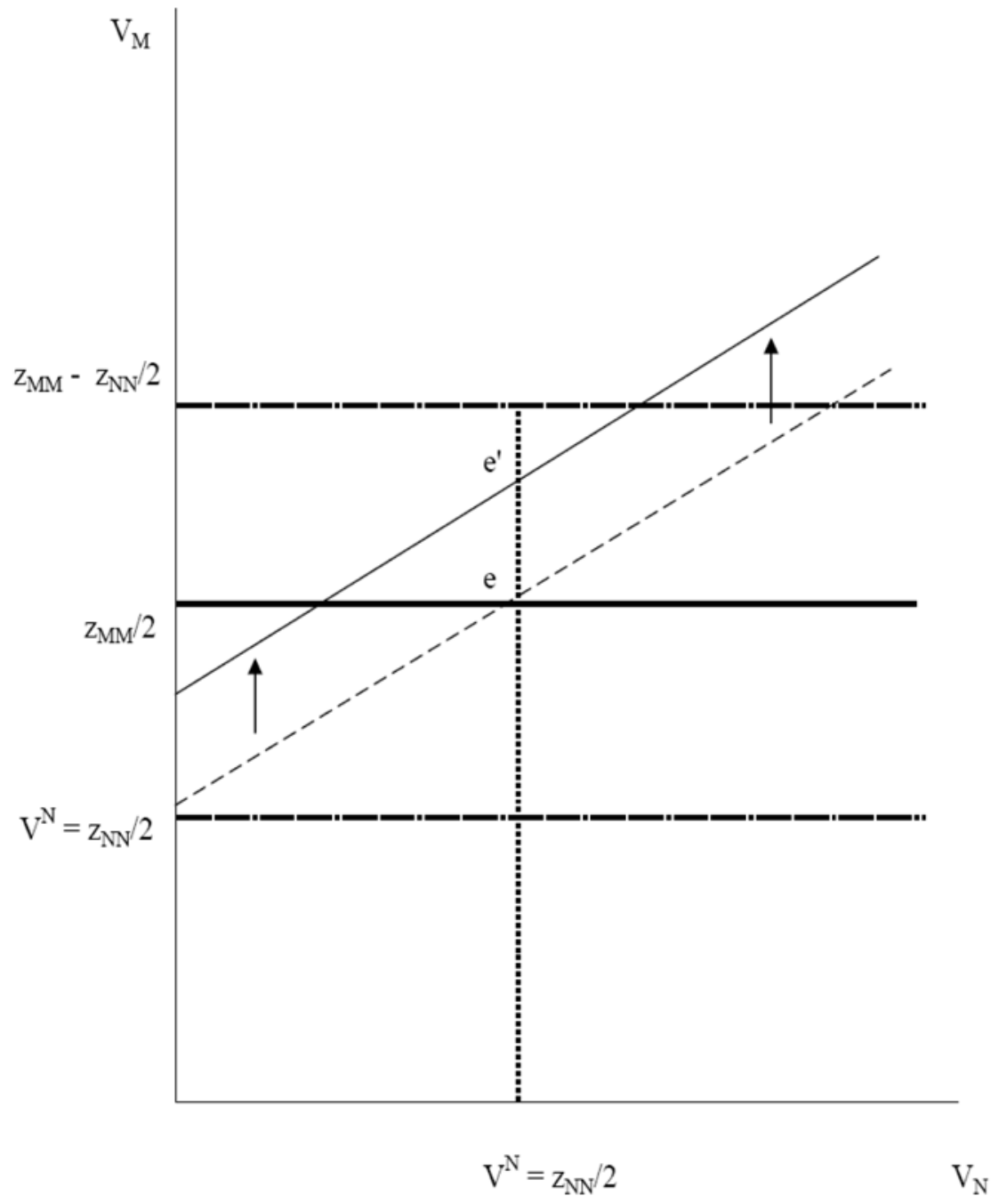


Figure 4: A Mixed Equilibrium with a Shortage of Committed Men

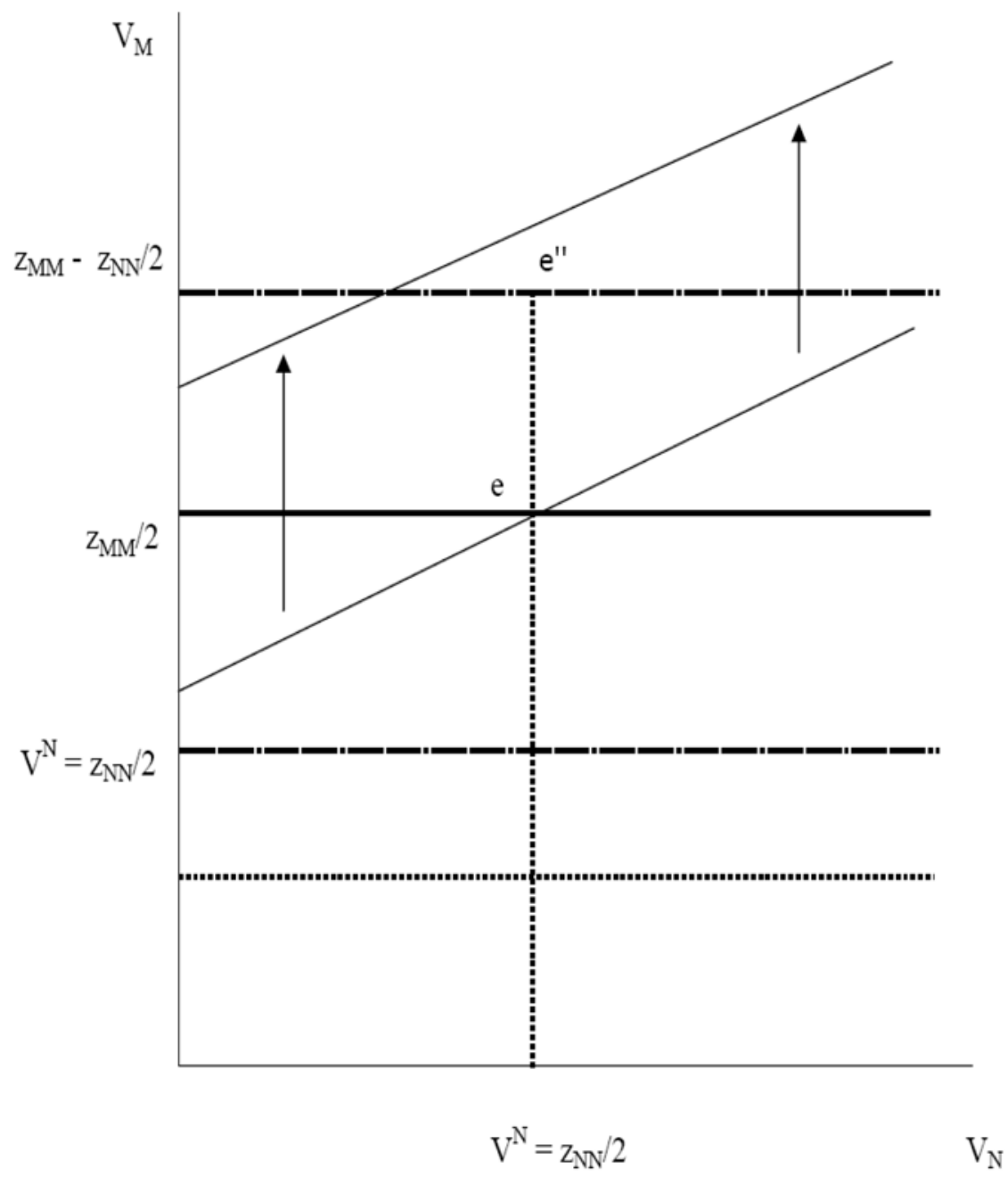


Figure 5: The Impact of an Increase in the Sex Ratio $r$

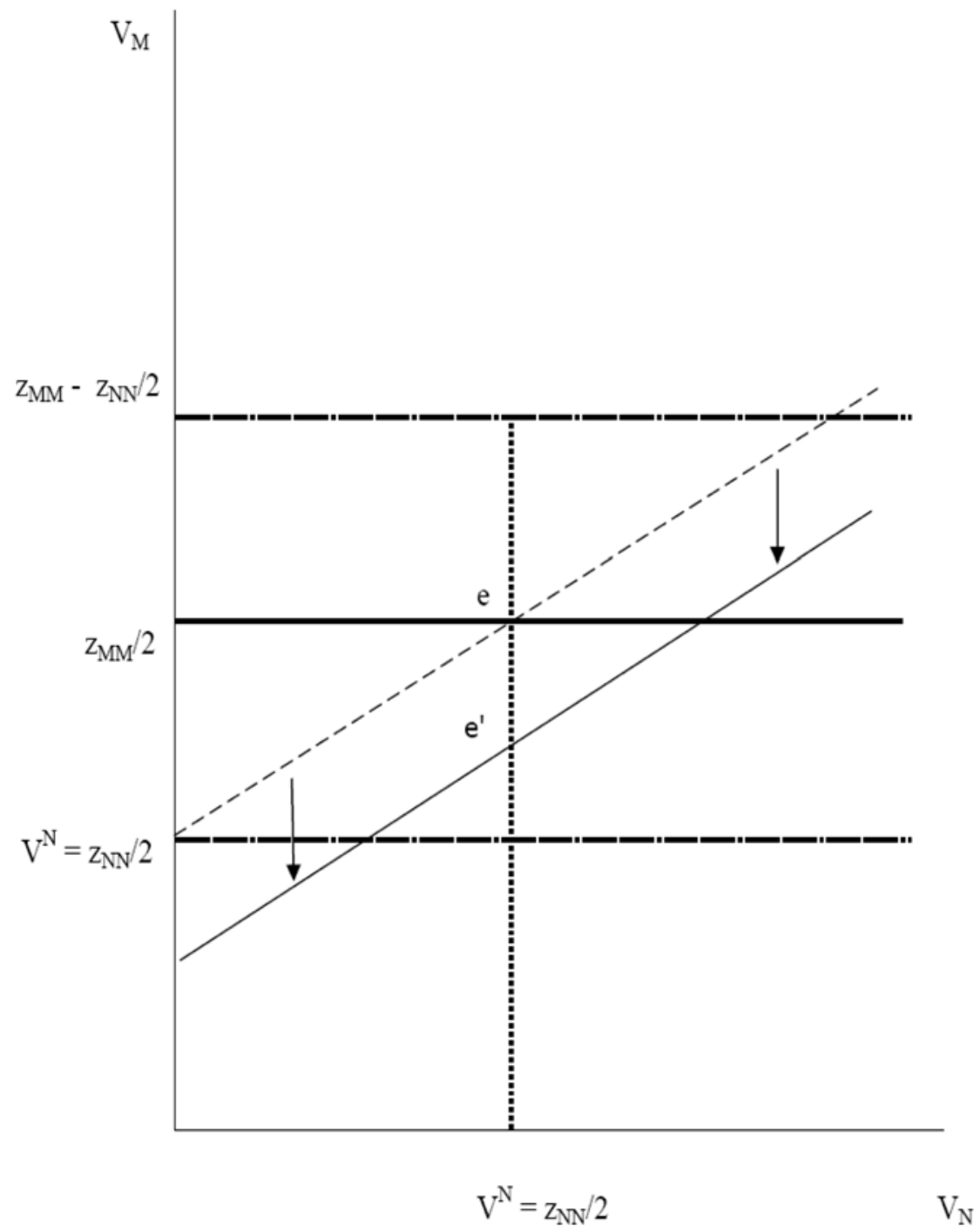

